\title{
Capacitative $\mathrm{Ca}^{2+}$ Entry via Orai1 and Stromal Interacting Molecule 1 (STIM1) Regulates Adenylyl Cyclase Type 8
}

\author{
Agnes C. L. Martin, Debbie Willoughby, Antonio Ciruela, Laura-Jo Ayling, Mario Pagano, \\ Sebastian Wachten, Anders Tengholm, and Dermot M. F. Cooper
}

Department of Pharmacology, University of Cambridge, Cambridge, United Kingdom (A.C.L.M., D.W., A.C., L.-J.A., M.P., S.W., D.M.F.C.); and Department of Medical Cell Biology, Uppsala University, Biomedical Centre, Uppsala, Sweden (A.T.)

Received September 3, 2008; accepted January 22, 2009

\begin{abstract}
Capacitative $\mathrm{Ca}^{2+}$ entry (CCE), which occurs through the plasma membrane as a result of $\mathrm{Ca}^{2+}$ store depletion, is mediated by stromal interacting molecule 1 (STIM1), a sensor of intracellular $\mathrm{Ca}^{2+}$ store content, and the pore-forming component Orai1. However, additional factors, such as C-type transient receptor potential (TRPC) channels, may also participate in the CCE apparatus. To explore whether the store-dependent $\mathrm{Ca}^{2+}$ entry reconstituted by coexpression of Orai1 and STIM1 has the functional properties of CCE, we used the $\mathrm{Ca}^{2+}$-calmodulin stimulated adenylyl cyclase type 8 (AC8), which responds selectively to CCE, whereas other modes of $\mathrm{Ca}^{2+}$ entry, including those activated by arachidonate and the ionophore ionomycin, are ineffective. In addition, the $\mathrm{Ca}^{2+}$ entry mediated by previous CCE candidates,
\end{abstract}

diacylglycerol-activated TRPC channels, does not activate AC8. Here, we expressed Orai1 and STIM1 in HEK293 cells and saw a robust increment in CCE, and a proportional increase in CCEstimulated AC8 activity. Inhibitors of the CCE assembly process ablated the effects on cyclase activity in both AC8-overexpressing HEK293 cells and insulin-secreting MIN6 cells endogenously expressing $\mathrm{Ca}^{2+}$-sensitive $\mathrm{AC}$ isoforms. AC8 is believed to be closely associated with the source of CCE; indeed, not only were AC8, Orai1, and STIM1 colocalized at the plasma membrane but also all three proteins occurred in lipid rafts. Together, our data indicate that Orai1 and STIM1 can be integral components of the cAMP and CCE microdomain associated with adenylyl cyclase type 8.
The complexity of signaling by the ubiquitous second messenger cAMP is enhanced by multiple regulatory susceptibilities of its synthesis by adenylyl cyclases (AC) and degradation by phosphodiesterases. Indeed, ACs receive regulatory signals from multiple sources, such as G-proteins, protein kinases, growth factors, and $\mathrm{Ca}^{2+}$ (for review, see Sunahara et al., 1996; Willoughby and Cooper, 2007). Nine transmembrane $\mathrm{AC}$ isoforms have been identified, four of which are sensitive to $\mathrm{Ca}^{2+}$; the cation stimulates $\mathrm{AC} 1$ and $\mathrm{AC} 8$ via calmodulin and inhibits AC5 and AC6 directly. AC8 is an

This work was supported by the National Institutes of Health National Institute of Neurological Disorders and Stroke [Grant NS28389]; The Wellcome Trust [Grant RG31760]; the European Union [Grant QLK3-CT-200202149]; European Foundation for the Study of Diabetes/MSD; the Swedish Research Council; the Swedish Diabetes Association; the Novo Nordisk Foundation; and the Family Ernfors Foundation.

Article, publication date, and citation information can be found at http://molpharm.aspetjournals.org.

doi:10.1124/mol.108.051748. archetypal calmodulin-stimulated enzyme, employing a disinhibitory activation mechanism ( $\mathrm{Gu}$ and Cooper, 1999; Simpson et al., 2006). However, AC8 is extremely discerning in its responsiveness to elevation of the cytoplasmic $\mathrm{Ca}^{2+}$ concentration $\left(\left[\mathrm{Ca}^{2+}\right]_{\mathrm{i}}\right)$. For example, release of $\mathrm{Ca}^{2+}$ from intracellular stores is relatively ineffective (Fagan et al., 1996). Even more remarkably, the substantial entry of $\mathrm{Ca}^{2+}$ at the plasma membrane mediated by arachidonate (Shuttleworth and Thompson, 1999), the diacylglycerol analog 1-oleyl-2-acetyl-snglycerol (OAG) (Martin and Cooper, 2006), and the ionophore ionomycin (Fagan et al., 1996) are also ineffective. In nonexcitable cells, only capacitative $\mathrm{Ca}^{2+}$ entry (CCE), which is triggered by the depletion of intracellular $\mathrm{Ca}^{2+}$ stores, can activate AC8 (Fagan et al., 1996).

The selective activation of $\mathrm{AC} 8$ by $\mathrm{CCE}$ is proposed to arise from a close apposition between the enzyme and CCE channels (Fagan et al., 1996; Gu and Cooper, 2000). Moreover,

ABBREVIATIONS: AC, adenylyl cyclase; OAG, 1-oleyl-2-acetyl-sn-glycerol; CCE, capacitative $\mathrm{Ca}^{2+}$ entry; STIM1, stromal interacting molecule 1; HEK, human embryonic kidney; ER, endoplasmic reticulum; 2-APB, 2-aminoethoxydiphenyl borate; YFP, yellow fluorescent protein; HA, hemagglutinin; PCR, polymerase chain reaction; CRAC, $\mathrm{Ca}^{2+}$ release-activated $\mathrm{Ca}^{2+}$; AEBSF, 4-(2-aminoethyl)benzenesulfonyl fluoride; SES, standard external solution; RT, room temperature; TG, thapsigargin; TBS, Tris-buffered saline; TTBS, Tris-buffered saline/Tween 20; MES, 2-(N-morpholino)ethanesulfonic acid; PBS, phosphate-buffered saline; FRET, fluorescence resonance energy transfer; CFP, cyan fluorescent protein; bp, base pair(s); ANOVA, analysis of variance; Epac1-camps, Epac1-based fluorescent cAMP sensor; TRPC, C-type transient receptor potential. 
AC8 is confined to lipid raft microdomains of the plasma membrane (Smith et al., 2002), which are enriched in cholesterol and sphingolipids (Simons and Ikonen, 1997) that seem to play an essential role in juxtaposing interacting signaling molecules. Indeed, disrupting lipid rafts by depleting cellular cholesterol prevents the regulation by CCE of both the endogenous $\mathrm{Ca}^{2+}$-inhibitable AC6 of $\mathrm{C} 6-2 \mathrm{~B}$ cells (Fagan et al., 2000) and heterologously expressed $\mathrm{Ca}^{2+}$-stimulable AC8 in human embryonic kidney (HEK) 293 cells (Smith et al., 2002).

The molecular identity and activation mechanism of the CCE channel has been elusive; however, key proteins of the CCE pathway have recently been identified. Stromal interacting molecule 1 (STIM1) has a single transmembranespanning domain, it is expressed in the membrane of the endoplasmic reticulum (ER), and its luminal domain contains a $\mathrm{Ca}^{2+}$-binding $\mathrm{EF}$ hand motif that enables it to respond to the $\mathrm{Ca}^{2+}$ content of intracellular stores (Liou et al., 2005; Roos et al., 2005). Upon store depletion, STIM1 clusters within the ER membrane (Stathopulos et al., 2006) to form puncta in regions close to the plasma membrane (Wu et al., 2006). Consequently, STIM1 is proposed to be the $\mathrm{Ca}^{2+}$ storesensing component of the CCE pathway (Zhang et al., 2005). Shortly after the discovery of STIM1, Orai1, also termed $\mathrm{Ca}^{2+}$ release-activated $\mathrm{Ca}^{2+}$ (CRAC) modulator 1 or CRACM1, a previously unknown protein, was put forward as a key CCE channel component (Feske et al., 2006). This widely expressed protein, which has four transmembranespanning domains, is localized in the plasma membrane. Although it has no sequence homology to other known ion channels, mutation of conserved residues in its putative pore region alters the properties of CCE (Prakriya et al., 2006; Vig et al., 2006; Yeromin et al., 2006).

Coexpression of Orai1 and STIM1 amplifies both CCE and the CRAC current, which suggests that these two proteins are the only rate-limiting components of the CCE pathway (Mercer et al., 2006; Peinelt et al., 2006; Soboloff et al., 2006). However, the members of the TRPC family of $\mathrm{Ca}^{2+}$ channels have received much attention as CCE candidates in the past and are still proposed to play a role in this pathway. Not only have interactions between TRPCs and Orai1 been detected (Liao et al., 2007; Ong et al., 2007; Jardin et al., 2008; Liao et al., 2008) but also regulation of TRPCs by STIM1 has been reported (Huang et al., 2006; López et al., 2006). Thus, although it is established that Orai1 and STIM1 produce storedependent $\mathrm{Ca}^{2+}$ entry, it is unclear whether this $\mathrm{Ca}^{2+}$ entry displays all the functional properties of CCE.

In this study, AC8 was used as a discerning physiological reporter of $\mathrm{CCE}$ to assess the $\mathrm{Ca}^{2+}$ entry reconstituted by coexpression of Orai1 and STIM1 in HEK 293 cells. Pharmacological blockade of the translocation of STIM1 from the ER to the plasma membrane markedly suppressed $\mathrm{Ca}^{2+}$-dependent cAMP formation, supporting a role of STIM1 in mediating CCE-dependent stimulation of AC8. Similar results were obtained from insulin-secreting MIN6 cells endogenously expressing AC8. Furthermore, AC8, Orai1 and STIM1 were all found to colocalize in lipid rafts. These findings underline the utility of AC8 to identify functional CCE in native and non-native systems; they substantiate the proposed role of Orai1 and STIM1 as essential elements of CCE and suggest an intimate association between $\mathrm{Ca}^{2+}$-sensitive $\mathrm{ACs}$ and elements of the CCE apparatus.

\section{Materials and Methods}

Materials. Fura-2/acetyoxymethyl ester and Pluronic F-127 were purchased from Invitrogen (Paisley, UK). DNase was from GE Healthcare (Chalfont St. Giles, Buckinghamshire, UK). Thapsigargin, 2-aminoethoxydiphenyl borate (2-APB), and 1-(5-chloronaphthalene-1-sulfonyl) homopiperazine, $\mathrm{HCl}$ (ML-9) were purchased from Calbiochem (Nottingham, UK). All other chemicals and culture media were from Sigma (Poole, UK), BDH (Poole, UK), or Thermo Fisher Scientific (Loughborough, UK).

cDNA Plasmid Constructs. Full-length human STIM1 in pcDNA3.1/Zeo was a gift from Kenneth Stauderman (University of California, Irvine, CA). STIM1 tagged at the N terminus with YFP was a gift from Tobias Meyer (Stanford University School of Medicine, Stanford, CA). Human Orai1 was purchased from Origene (Rockville, MD) and cloned into pcDNA3.1/myc (Invitrogen) between the restriction sites $\mathrm{KpnI}$ and EcoRI. An HA tag was added to the $\mathrm{C}$ terminus of rat AC8 by PCR, and this insert was cloned into pcDNA 3.0 between the restriction sites $\mathrm{KpnI}$ and $\mathrm{XbaI}$. To generate an $\mathrm{N}$-terminally CFP-tagged AC8 construct, AC8 was cloned between the restriction sites Apa1 and Xba1 of pECFP-C1. Epac1-based fluorescent cAMP sensor (Epac1-camps) was a gift from Martin Lohse (Universität Würzburg, Würzburg, Germany).

Cell Culture and Transient Transfection of Cells. HEK293 cells were cultured in Eagle's minimal essential medium, supplemented with $10 \%$ fetal bovine serum, $50 \mu \mathrm{g} / \mathrm{ml}$ penicillin, $50 \mu \mathrm{g} / \mathrm{ml}$ streptomycin, $100 \mu \mathrm{g} / \mathrm{ml}$ neomycin and $2 \mathrm{mM}$ L-glutamine. Mouse insulin-secreting MIN6 $\beta$-cells were cultured in Dulbecco's modified Eagle's medium containing $4500 \mathrm{mg} / \mathrm{ml}$ glucose, supplemented with $15 \%$ fetal bovine serum, $100 \mathrm{U} / \mathrm{ml}$ penicillin, $100 \mu \mathrm{g} / \mathrm{ml}$ streptomycin, $2 \mathrm{mM}$ L-glutamine, and $50 \mu \mathrm{M} 2$-mercaptoethanol. All cells were maintained at $37^{\circ} \mathrm{C}$ in a humidified atmosphere of $5 \% \mathrm{CO}_{2} / 95 \%$ air. One day before transient transfection with STIM1, Orai1-myc or Epac1-camps, cells were plated on 100-mm diameter dishes or on 25 -mm poly-L-lysine-coated coverslips at $\sim 60 \%$ confluence. The Lipofectamine 2000 method of transfection (Invitrogen) was adopted, following the manufacturer's instructions and using 1 or $0.5 \mu \mathrm{g}$ total cDNA for $100-\mathrm{mm}$ dishes or $25-\mathrm{mm}$ coverslips, respectively. Cells were used 2 days after transfection.

Generation of Stable Cell Lines. To generate cells stably expressing AC8 or AC8-HA, HEK293 cells were plated on 100-mm dishes at $\sim 50 \%$ confluence 1 day before transfection with $2 \mu \mathrm{g}$ of AC8 or AC8-HA cDNA with the $\mathrm{Ca}_{3}\left(\mathrm{PO}_{4}\right)_{2}$ method (Chen and Okayama, 1987). Two days after transfection, the culture medium was replaced with fresh medium containing $800 \mu \mathrm{g} / \mathrm{ml} \mathrm{G}-418$ disulfate (Formedium Ltd., Hunstanton, Norfolk, UK) to select transfected cells. After selection, cells were maintained in medium containing 400 $\mu \mathrm{g} / \mathrm{ml} \mathrm{G}-418$.

Preparation of HEK293 Cell Membranes. Crude membranes were prepared, as described previously (Nakahashi et al., 1997), from HEK293 cells coexpressing AC8-HA, Orai1-myc, and STIM1. In brief, cells were sheared by passage through a 21-gauge needle, 10 times, in homogenization buffer $\left(2 \mathrm{mM} \mathrm{MgCl}_{2}, 1 \mathrm{mM}\right.$ EDTA, $1 \mathrm{mM}$ AEBSF, $1 \mathrm{mM}$ benzamidine, $1 \mu \mathrm{g}$ of DNase, and $50 \mathrm{mM}$ Tris, $\mathrm{pH}$ 7.4). Membranes were collected by centrifugation $\left(23,000 \mathrm{~g}, 15 \mathrm{~min}, 4^{\circ} \mathrm{C}\right)$, resuspended in buffer containing $40 \mathrm{mM}$ Tris-Cl, $800 \mu \mathrm{M}$ EGTA, $0.25 \%$ bovine serum albumin (fraction $\mathrm{V}$ ), $\mathrm{pH} 7.4$, and stored in liquid nitrogen.

Preparation of HEK293 Cell Lysate. Cells coexpressing AC8HA, Orai1-myc, and STIM1 were washed in standard external solution (SES; $150 \mathrm{mM} \mathrm{NaCl}, 0.5 \mathrm{mM} \mathrm{KCl}, 0.5 \mathrm{mM} \mathrm{MgCl}_{2}, 1 \mathrm{mM} \mathrm{CaCl}_{2}$, $10 \mathrm{mM}$ glucose, and $10 \mathrm{mM}$ HEPES, $\mathrm{pH}$ 7.4). Cells were incubated for $3 \mathrm{~min}$ at room temperature (RT) with SES containing $1 \mu \mathrm{M}$ thapsigargin (TG), then washed in SES. Cells were washed on ice with chilled phosphate-buffered saline containing $1 \times$ protease inhibitor cocktail (Sigma), after which $1 \mathrm{ml}$ of radioimmunoprecipitation assay buffer was applied [1\% (v/v) Nonidet P-40, 1\% (v/v) deoxycholate, $0.1 \%(\mathrm{w} / \mathrm{v}) \mathrm{SDS}, 150 \mathrm{mM} \mathrm{NaCl}, 50 \mathrm{mM}$ Tris-HCl, and $1 \times$ 
protease inhibitor cocktail]. Cells were scraped, stored overnight at $-80^{\circ} \mathrm{C}$, lysed using a 21-gauge needle and centrifuged at $100,000 \mathrm{~g}$, $4^{\circ} \mathrm{C}$ for $30 \mathrm{~min}$. Protein content of the supernatant was estimated using the bicinchoninic acid assay kit (Sigma).

Western Blotting. Proteins were resolved using 6, 8, and $12 \%$ (w/v) SDS-polyacrylamide gels for AC8-HA, STIM1, and Orai1-myc, respectively. Proteins were transferred to a nitrocellulose membrane for $90 \mathrm{~min}$ at $300 \mathrm{~mA}$. Membranes were then incubated in TBS (20 $\mathrm{mM}$ Tris, $\mathrm{pH} 7.5$, and $150 \mathrm{mM} \mathrm{NaCl}$ ) containing $5 \%$ (w/v) nonfat dry milk for $30 \mathrm{~min}$, followed by three 5 -min washes in TBS supplemented with $0.05 \%(\mathrm{v} / \mathrm{v})$ Tween 20 (TTBS). Membranes were incubated overnight at RT with anti-HA monoclonal antibody (1:5000; Sigma), anti-STIM1 monoclonal antibody (1:250; BD Transduction Laboratories, Lexington, KY), anti-myc monoclonal antibody (1:1000; Santa Cruz Biotechnology), anti-caveolin polyclonal antibody (1:5000; BD Transduction Laboratories), or anti- $\beta$-adaptin polyclonal antibody (1:5000; Santa Cruz Biotechnology) in TTBS containing $1 \%$ nonfat dry milk. The membranes were washed (three times for $5 \mathrm{~min}$ each) in TTBS and then incubated with goat anti-mouse IgG conjugated to horseradish peroxidase (1:5000; Promega, Madison, WI) or Trueblot anti-mouse antibody (1:2500; Insight Biotechnology Ltd., Wembley, Middlesex, UK) for immunoprecipitated samples, in TTBS/1\% milk for $1 \mathrm{~h}$. Finally, the membranes were washed in TTBS $(3 \times 5 \mathrm{~min})$, rinsed in TBS, and visualized with ECL Plus reagent (GE Healthcare).

Membrane Fractionation. Lipid raft and nonlipid raft membranes were separated by a procedure that exploited their different buoyancies as described previously (Crossthwaite et al., 2005). After treatment with $0.1 \mu \mathrm{M}$ TG for 5 min, transfected HEK293 cells were pelleted and resuspended in ice-cold sodium carbonate solution (500 $\mathrm{mM} \mathrm{Na}_{2} \mathrm{CO}_{3}, \mathrm{pH}$ 11) before sonication (Sonic Dismembrator; Thermo Fisher Scientific). After homogenization, the suspension was adjusted to $40 \%$ sucrose by the addition of $60 \%$ sucrose in MES buffer (50 mM MES, $150 \mathrm{mM} \mathrm{NaCl}$, and $250 \mathrm{mM} \mathrm{Na}_{2} \mathrm{CO}_{3}$, $\mathrm{pH}$ 6.4). The extract was placed below a $5 \%$ and $30 \%$ discontinuous sucrose gradient prepared in ice-cold MES buffer and centrifuged in a rotor (SW55; Beckman Coulter, Fullerton, CA) at 24,000 rpm for $16 \mathrm{~h}$ at $4^{\circ} \mathrm{C}$. Fractions $(10 \times 0.5 \mathrm{ml})$ were collected from the top of the gradient, diluted in 5 volumes of MES buffer and centrifuged in the Beckman SW55 rotor at 50,000 rpm for $1 \mathrm{~h}$ at $4^{\circ} \mathrm{C}$. Pelleted membranes were resuspended in 1\% SDS containing $8 \mathrm{M}$ urea, suspended in loading buffer, heated to $37^{\circ} \mathrm{C}$ for $30 \mathrm{~min}$, and stored $\left(-80^{\circ} \mathrm{C}\right)$.

Confocal Imaging. Cells were plated onto $25 \mathrm{~mm}$ poly-L-lysinecoated coverslips, transfected as indicated, and incubated for $5 \mathrm{~min}$ at RT in extracellular buffer $(140 \mathrm{mM} \mathrm{NaCl}, 4 \mathrm{mM} \mathrm{KCl}, 0.2 \mathrm{mM}$ $\mathrm{MgCl}_{2}, 11 \mathrm{mM}$ D-glucose, and $10 \mathrm{mM}$ HEPES, $\mathrm{pH}$ 7.4) supplemented with $0.1 \mathrm{mM}$ EGTA and $0.2 \mu \mathrm{M}$ TG. Cells were then fixed in $4 \%$ paraformaldehyde for $15 \mathrm{~min}$. For the detection of Orai1-myc by immunocytochemistry, cells were permeabilized in $0.1 \%$ Triton $\mathrm{X}-100$ for $15 \mathrm{~min}$, blocked in $10 \%$ goat serum for $1 \mathrm{~h}$, and incubated for $2 \mathrm{~h}$ at RT with anti-myc monoclonal antibody $(1 \mu \mathrm{g} / \mathrm{ml}$; Santa Cruz Biotechnology) diluted in PBS supplemented with $1.5 \%$ goat serum. Cells were washed three times in PBS before incubation for $1 \mathrm{~h}$ at RT with Alexa Fluor 555-conjugated anti-mouse goat secondary antibody (10 $\mu \mathrm{g} / \mathrm{ml}$; Invitrogen) diluted in PBS supplemented with $1.5 \%$ goat serum, followed by three washes in PBS. Primary and secondary antibody controls were performed by the addition of either the primary or the secondary antibody alone; no significant autofluorescence or nonspecific binding was detected for either antibody. Images were captured with a Leica SP5 confocal microscope running LAS AF 1.6.0 software using a $63 \times$ plan apochromat 1.4 numerical aperture oil immersion objective. Cells expressing CFP-AC8 and YFP-Stim1 were visualized using the $458 \mathrm{~nm}$ and $514 \mathrm{~nm}$ laser lines, respectively, and cells expressing Orai1-myc were visualized with the $514 \mathrm{~nm}$ line after immunodetection of the epitope-tag as described above. Cells expressing single chromophores were used to adjust the laser intensity and the emission collection range to eliminate bleed-through into different channels.
Measurement of $\left[\mathrm{Ca}^{\mathbf{2 +}}\right]_{\mathbf{i}}$ in Single Cells. HEK293 were plated onto $25 \mathrm{~mm}$ poly-L-lysine coated coverslips, transfected as indicated and loaded with fura-2/acetoxymethyl ester $(2 \mu \mathrm{M})$ and $0.02 \%$ Pluronic F-127 for $40 \mathrm{~min}$ at room temperature in extracellular saline containing $140 \mathrm{mM} \mathrm{NaCl}, 4 \mathrm{mM} \mathrm{KCl}, 0.2 \mathrm{mM} \mathrm{MgCl}_{2}, 11 \mathrm{mM}$ Dglucose, and $10 \mathrm{mM}$ HEPES, pH 7.4, supplemented with $1 \mathrm{mM}$ $\mathrm{CaCl}_{2}$. MIN6 cells were loaded with fura-2 in the same manner using an extracellular saline containing $125 \mathrm{mM} \mathrm{NaCl}, 4.8 \mathrm{mM} \mathrm{KCl}, 1.2$ $\mathrm{mM} \mathrm{MgCl}_{2}, 3 \mathrm{mM}$ D-glucose, and $25 \mathrm{mM}$ HEPES, $\mathrm{pH}$ 7.4, supplemented with $1.3 \mathrm{mM} \mathrm{CaCl}_{2}$. After loading either cell type, cells were washed several times and then briefly equilibrated in $\mathrm{Ca}^{2+}$-free extracellular buffer containing $0.1 \mathrm{mM}$ EGTA. Cells were imaged using a CoolSNAP-HQ charge-coupled device camera (Photometrics, Tucson, AZ) and monochromator system (Cairn Research, Kent, UK) attached to a Nikon TMD microscope $(40 \times$ objective; Nikon, Tokyo, Japan). Emission images (D510/80M) at $340 \mathrm{~nm}$ and $380 \mathrm{~nm}$ excitation were collected every second using MetaFluor software (Molecular Devices, Sunnyvale, CA). Data were plotted as 340/380 nm ratio changes relative to the fluorescence ratio before the addition of extracellular $\mathrm{Ca}^{2+}(\Delta 340 / 380)$.

Measurement of $[\mathrm{cAMP}]_{\mathbf{i}}$ in Single Cells by FRET. $[\mathrm{cAMP}]_{\mathrm{i}}$ was monitored in single cells by measuring the fluorescence of transiently expressed Epac1-camps (Nikolaev et al., 2004). HEK293 cells or MIN6 cells were equilibrated for $30 \mathrm{~min}$ at RT in extracellular saline (see Measurement of [cAMP], in Single Cells for composition). Fluorescence measurements were performed using an Ixon + camera (Andor, Belfast, Northern Ireland) and an Optosplit (505DC) to separate CFP (470 nm) and YFP (535 nm) emission images (Cairn Research, Kent, UK). For dual-emission ratio imaging, cells were excited at $436 \mathrm{~nm}$ with a monochromator (Cairn Research) and 51017 filter set (Chroma Technology Corp., Brattleboro, VT) attached to a Nikon eclipse TE2000-S microscope (40× objective). Emission images at $470 \mathrm{~nm}$ and $535 \mathrm{~nm}$ were collected every $3 \mathrm{~s}$ (250-ms integration time) and then background-subtracted and analyzed with Metamorph imaging software (Molecular Devices). Cells in which the CFP and YFP fluorescence intensity was less than twice the background fluorescence were excluded, as were cells with excessive expression of the fluorescent probe. FRET data are plotted as changes in background subtracted $470 \mathrm{~nm}$ versus $535 \mathrm{~nm}$ (CFP/YFP) emission ratio for each individual cell.

Semiquantitative PCR on MIN6 cDNA. Total RNA was prepared from MIN6 cells using the RNeasy Plus Mini Kit (QIAGEN, Hilden, Germany) according to the manufacturer's instructions. One $\mu \mathrm{g}$ of total RNA was transcribed into cDNA using SuperScript II Reverse Transcriptase (Invitrogen). Primers specific for both the mouse and the rat genes were designed to amplify DNA fragments of defined lengths from AC8 (745 bp), AC6 (834 bp), and AC2 (888 bp). Primer sequences are given from $5^{\prime}$ to $3^{\prime}$. AC8, 5' (GCCAGAGGCGCAAATCGG) and 3'(GGTAAATCCTTTGACATCTGC); AC6, 5' (GCATCCTAGCAGCCGTGC) and 3'(CAGACATCAAACTGCCATTTC); AC2, 5'(GTTCTGGCAGATACTGGCC) and 3'(CAGAGTGTGTCGAGGTCTG). The DNA fragments were amplified from $400 \mathrm{ng}$ of MIN6 cDNA using the KOD Hot-Start DNA polymerase (Novagen). Reactions containing $1 \mathrm{ng}$ of plasmid DNA, encoding the respective fulllength cDNAs of AC8(rat), AC6(rat), or AC2(rat), were carried out as positive controls.

Amplified fragments were separated on a 1\% agarose gel and visualized with SafeView nucleic acid stain (NBS Biologicals). Digital images were generated with the Gene Flash imaging station (Syngene Bioimaging, Frederick, MD), and analyzed using the ImageJ software (http://rsbweb.nih.gov/ij/). Band intensities of the fragments amplified from MIN6 cDNA were related to the intensities of the respective positive controls, and finally normalized to AC2. Averages \pm S.D. were calculated from three independent experiments. 


\section{Results}

AC8, Orai1, and STIM1 Are Colocalized in Lipid Raft Domains of the Plasma Membrane. This study investigates the ability of Orai1 and STIM1 to reconstitute functional CCE by using AC8 as a physiological sensor of CCE. Although Orai1 and STIM1 are endogenously expressed in HEK293 cells, the present study relies partly on overexpression of these proteins in conjunction with AC8. To facilitate detection, the proteins were fused to epitope tags, the type and position of which were chosen to minimize hindrance; C-terminally myc-tagged Orai1 and N-terminally YFPtagged STIM1 have been well characterized (Liou et al., 2005; Prakriya et al., 2006; Gwack et al., 2007), and both C-terminally HA-tagged and N-terminally CFP-tagged AC8 displayed activity identical to untagged AC8 (data not shown).

Coexpression of AC8-HA, Orai1-myc, and untagged STIM1 was verified by Western blot analysis of cellular membranes (Fig. 1A). AC8-HA and Orai1-myc were detected using the antibodies directed against their epitope tags; hence no sig- nal was present in samples from untransfected cells. The anti-STIM1 antibody, however, revealed endogenous STIM1 in untransfected samples. STIM1, Orai1, and AC8 are all post-translationally glycosylated, which may account for the fact that doublets are observed (Williams et al., 2002; Gwack et al., 2007; A. C. L. Martin and D. M. F. Cooper, unpublished observations, respectively).

The selective regulation of $\mathrm{AC} 8$ by CCE seems to arise from a close apposition of the enzyme and the CCE channel (Fagan et al., 1996; Gu and Cooper, 2000). Confocal analysis of cells coexpressing CFP-AC8, YFP-STIM1, and Orai1-myc revealed that all three proteins are colocalized at the plasma membrane after store depletion (Fig. 1B); Orai1 and AC8 are localized to the plasma membrane regardless of intracellular $\mathrm{Ca}^{2+}$ store-filling, whereas the distribution of STIM 1 is initially punctate throughout the cell, becoming more concentrated in the cell periphery, presumably at points of contact between the ER and the plasma membrane after depletion of intracellular stores with TG. The degree of expression of Orai1-myc and YFP-STIM1 is not detectably different
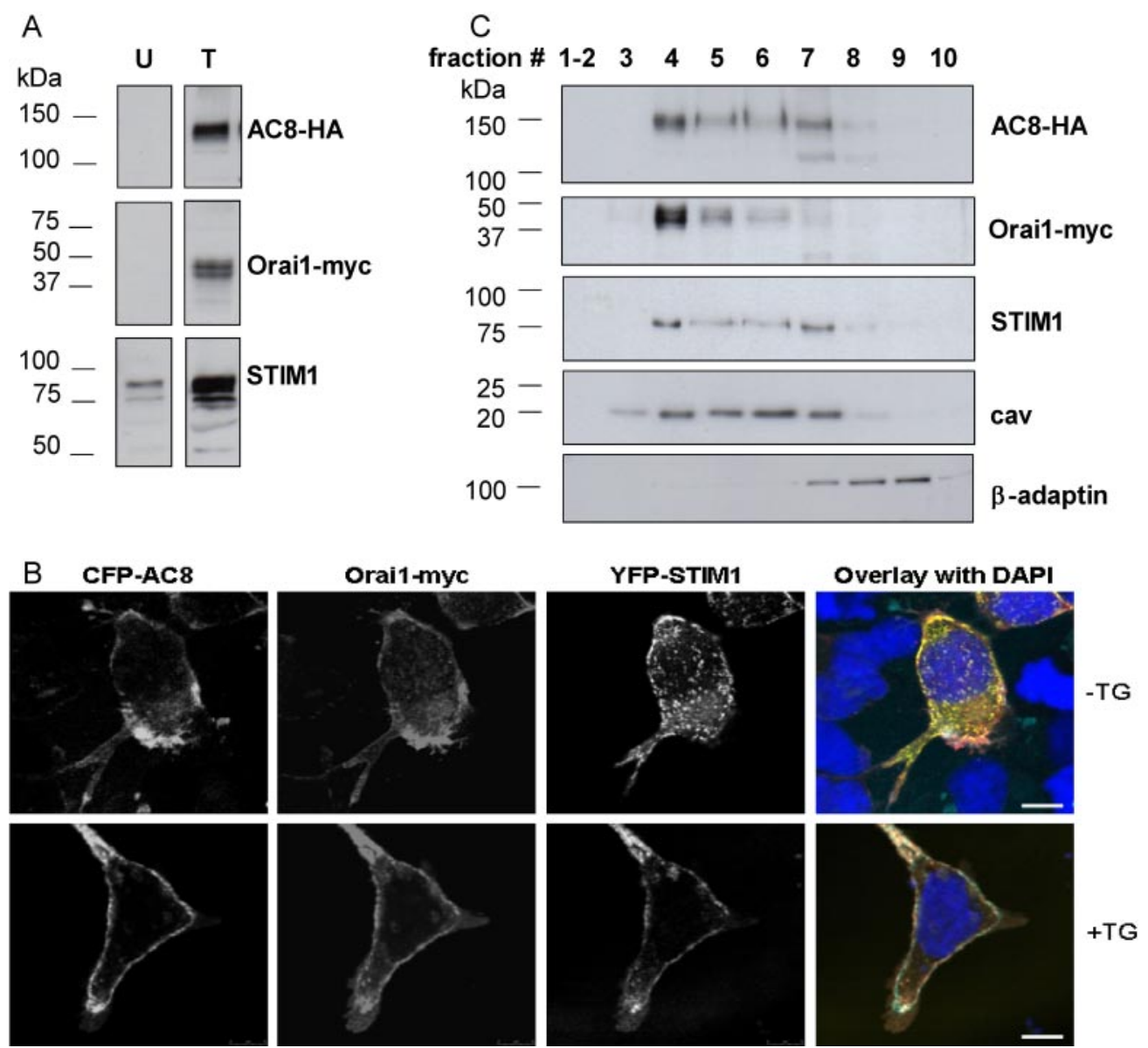

Fig. 1. Coexpressed Orai1, STIM1, and AC8 are colocalized in lipid raft domains of the plasma membrane. A, cellular membranes, prepared from either untransfected HEK293 cells (U) or HEK293 cells coexpressing AC8-HA, Orai1-myc, and STIM1 (T), were analyzed by SDS-polyacrylamide gel electrophoresis. Antibodies raised against the epitope-tags of AC8-HA and Orai1-myc confirmed their successful expression; the anti-STIM1 antibody detected endogenous STIM1 in untransfected samples and the increased signal in transfected samples confirmed that this protein is also successfully expressed. All three proteins migrated as doublets as a result of post-translational glycosylation. B, confocal analysis of cells coexpressing Orai1-myc, YFP-STIM1, and CFP-AC8 before and after intracellular $\mathrm{Ca}^{2+}$ store depletion with thapsigargin (TG). Orai1-myc and CFP-AC8 typically colocalize at the plasma membrane. YFP-STIM1 is localized throughout the cell in store-replete conditions and translocates to the plasma membrane in response to store depletion. In the overlay image, Orai1-myc is shown in red, YFP-STIM1 in yellow, AC8-CFP in cyan, and 4,6-diamidino-2-phenylindole staining of the nucleus is in dark blue. C, cellular membranes from cells coexpressing AC8-HA, Orai1-myc, and STIM1 were fractionated on a sucrose gradient to separate lipid raft from nonraft membranes. The three overexpressed proteins were present in lipid raft fractions of the gradient, as indicated by the lipid raft marker caveolin (cav), and absent from nonlipid raft fractions, highlighted by $\beta$-adaptin. 
against a control or AC8-stable expressing background (not shown). Because AC8 is localized in lipid raft microdomains of the plasma membrane, and its presence there is a requirement for its regulation by CCE (Smith et al., 2002), we sought to determine whether the same was true of Orai1 and STIM1. After TG treatment and cell sonication, membranes from HEK293 cells coexpressing AC8-HA, Orai1-myc, and STIM1 were separated on a sucrose gradient, on which lipid rafts are more buoyant. Successful fractionation was verified by probing the fractions of the gradient for caveolin, an established marker of lipid rafts, and for $\beta$-adaptin, a marker of nonlipid raft membranes (Crossthwaite et al., 2005). AC8-HA, Orai1myc, and STIM1 were all enriched in the same fractions as caveolin, indicating that all these proteins are present in lipid rafts (Fig. 1C).

Coexpression of Orai1-myc and STIM1 Enhances CCE. Previous reports showed that coexpression of Orai1 and STIM1 amplifies CCE in HEK293 cells (Mercer et al., 2006; Soboloff et al., 2006). We sought to replicate this observation by cotransfecting Orai1-myc and STIM1 in HEK293 cells stably expressing AC8 (HEK-AC8 cells). We monitored the cytoplasmic $\mathrm{Ca}^{2+}$ concentration $\left(\left[\mathrm{Ca}^{2+}\right]_{\mathrm{i}}\right)$ of individual cells loaded with the fluorescent $\mathrm{Ca}^{2+}$ indicator, fura-2. CCE was triggered by depletion of intracellular $\mathrm{Ca}^{2+}$ stores with TG $(0.2 \mu \mathrm{M})$ in $\mathrm{Ca}^{2+}$-free conditions, followed by addition of extracellular $\mathrm{Ca}^{2+}$.

The typical response of a control HEK-AC8 cell, transfected with empty pcDNA vector, is shown in Fig. 2A, in both store-depleted and store-replete conditions. After treatment with TG (first $\mathrm{Ca}^{2+}$ peak), a rapid and robust increase in $\left[\mathrm{Ca}^{2+}\right]_{\mathrm{i}}$ (second $\mathrm{Ca}^{2+}$ peak) was observed upon addition of extracellular $\mathrm{Ca}^{2+}(2 \mathrm{mM})$. In the absence of TG treatment, a modest, slow rise in $\left[\mathrm{Ca}^{2+}\right]_{\mathrm{i}}$ occurred. Images of representative cells transfected with pcDNA vector are shown at key points of the time course (Fig. 2B). Control experiments were also performed to confirm that overexpression of AC8 did not significantly affect CCE in the HEK293 cells (CCE in HEKAC8 cells was $101.7 \pm 2.9 \%$ of that seen in wild-type HEK293 cells $(n=42)$.

The same protocol for triggering CCE was applied to HEKAC8 cells expressing Orai1 alone, STIM1 alone, and Orai1 and STIM1 in combination (Fig. 2C). Images of representative HEK-AC8 cells coexpressing Orai1 and STIM1 are shown in Fig. 2B. Effects of protein expression on the $\mathrm{Ca}^{2+}$ peak attained upon addition of $\mathrm{Ca}^{2+}$ to the extracellular medium and the rate of $\mathrm{Ca}^{2+}$ entry were quantified and are summarized in Fig. 2D. Coexpression of Orai1 and STIM1 increased the magnitude of CCE by $\sim 50 \%$, which is consistent with the proposal that these two proteins reconstitute CCE. Individual transfection of each protein, however, also affected CCE. Expression of Orai1 alone caused a 20\% decrease in both the amplitude of the CCE response and the rate of $\mathrm{Ca}^{2+}$ entry, compared with pcDNA transfected controls, whereas STIM1 expression resulted in an increase of $\sim 25 \%$. The observed decrease of CCE in the presence of overexpressed Orai1 and modest increase in the presence of STIM1 is in agreement with previous reports (Mercer et al., 2006; Soboloff et al., 2006).

To address the possibility that Orai1 and STIM1 expression may affect store-independent $\mathrm{Ca}^{2+}$ entry, the effect of these proteins on the plasma membrane $\mathrm{Ca}^{2+}$ permeability in store-replete conditions was measured (Fig. 2, E and F). Overexpression of STIM1, both in the presence and absence of Orai1, caused only a very modest increase in $\mathrm{Ca}^{2+}$ leak, which cannot account for the observed increase in CCE. Further characterization of the CCE signal observed in HEKAC8 cells coexpressing Orai1 and STIM1 revealed that $\mathrm{Ca}^{2+}$ entry was completely blocked using $1 \mu \mathrm{M} \mathrm{Gd}^{3+}$ (data not shown) a well-established inhibitor of store-operated channels (Broad et al., 1999; Luo et al., 2001). The ability of $\mathrm{Gd}^{3+}$ to inhibit TG-induced $\mathrm{Ca}^{2+}$ entry in HEK293 cells overexpressing Orai1 and STIM1 accords with previous work by Mercer et al. (2006).

$\mathrm{Ca}^{2+}$ Entry Resulting from Orai1 and STIM1 Overexpression Regulates AC8. We used the selective activation of AC8 by CCE in nonexcitable cells as a physiological sensor of CCE, to determine whether Orai1 and STIM1 coexpression reconstitutes functional CCE. HEK293 cells stably expressing AC8 were transfected with either pcDNA vector as a control, Orai1 alone, STIM1 alone, or both Orai1 and STIM1 together. In addition, the cytosolic FRET-based cAMP sensor, comprising the cAMP binding domain of an exchange protein directly activated by cAMP (Epac1-camps) (Nikolaev et al., 2004), was cotransfected to monitor the intracellular cAMP concentration $\left([\mathrm{cAMP}]_{\mathrm{i}}\right)$ in individual cells. No $\mathrm{Ca}^{2+}$ stimulated ACs are expressed endogenously in HEK293 cells; hence, an increase in cAMP production in response to CCE should reflect AC8 activity (Fagan et al., 1996). Cells were also treated with a low concentration of the $\mathrm{G}_{\mathrm{s}}$-activator, prostaglandin $\mathrm{E}_{1}(10 \mathrm{nM})$ to potentiate the responsiveness of AC8 to $\mathrm{Ca}^{2+}$ (Willoughby and Cooper, 2006). CCE-activation of AC8 typically displays a clear dose dependence on the extracellular $\mathrm{Ca}^{2+}$ concentration $\left(\left[\mathrm{Ca}^{2+}\right]_{\mathrm{o}}\right)$. To avoid saturation of the highly sensitive Epac1-camps probe in cells expressing Orai1 and STIM1, $\left[\mathrm{Ca}^{2+}\right]_{o}$ was adjusted to $1 \mathrm{mM}$ (similar -fold changes in $\left[\mathrm{Ca}^{2+}\right]_{\mathrm{i}}$ were seen with 1 and $2 \mathrm{mM}$ extracellular $\mathrm{Ca}^{2+}$; data not shown).

The typical responses of pcDNA-transfected control HEKAC8 cells, in store-depleted and store-replete conditions, are depicted in Fig. 3A. In the absence of $\mathrm{Ca}^{2+}$, there was little response to prostaglandin $\mathrm{E}_{1}$. Addition of extracellular $\mathrm{Ca}^{2+}$ in store-depleted conditions produced a rapid increase in $[\mathrm{cAMP}]_{\mathrm{i}}$ consistent with CCE-dependent stimulation of AC8 activity. In contrast, the $\mathrm{Ca}^{2+}$ entry occurring upon addition of extracellular $\mathrm{Ca}^{2+}$ in store-replete conditions did not activate AC8.

In store-depleted conditions (Fig. 3, C and D), expression of Orai1 practically abolished the activation of AC8 (80\% inhibition), STIM1 caused a significant increase in both the amplitude and rate of activation (1.6- and 2.3-fold increases, respectively), whereas coexpression of Orai1 and STIM1 caused the greatest increase in cAMP production and rate of activation (2.2- and 2.8-fold increases, respectively). This result confirms that Orai1 and STIM1 reconstitute CCE and stimulate AC8 activity. Pseudocolor FRET ratio images from representative cells transfected with pcDNA or cotransfected with Orai1 and STIM1 are shown at key points of the time course and show enhanced CCE-mediated stimulation of AC8 in cells overexpressing Orai1 and STIM1 compared with pcDNA controls (Fig. 3B).

The contribution of the $\mathrm{Ca}^{2+}$ leak to the activation of AC8 was minimal in all conditions tested (Fig. 3, E and F). 


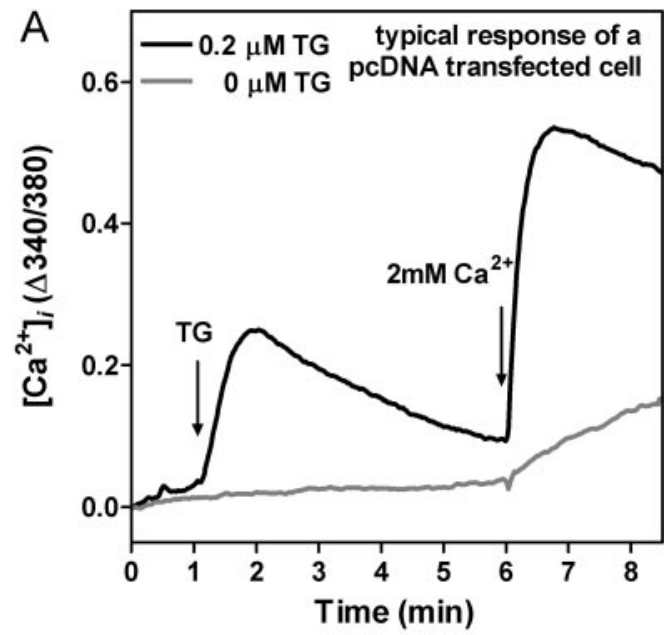

B
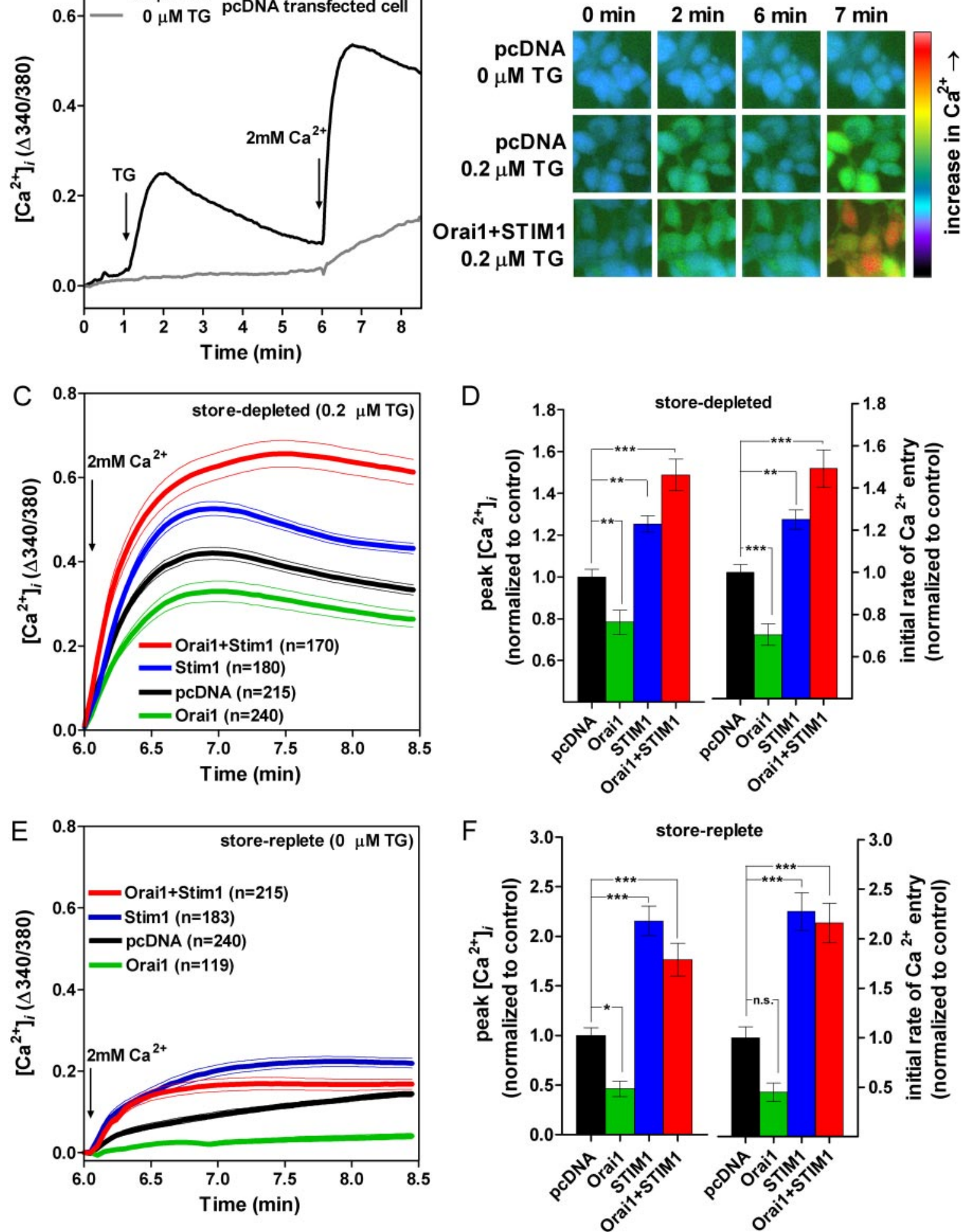

Fig. 2. Coexpression of Orai1-myc and STIM1 enhances CCE in HEK293 cells. A, $\left[\mathrm{Ca}^{2+}\right]_{\mathrm{i}}$ was monitored in HEK-AC8 cells coexpressing Orai1-myc and STIM1. Individual traces of typical pcDNA-transfected control cells are shown. Stores were depleted with $0.2 \mu \mathrm{M}$ TG to prime the cells for CCE, which was then triggered by addition of $2 \mathrm{mM} \mathrm{Ca}^{2+}$. In the absence of TG treatment, a small component of noncapacitative Ca ${ }^{2+}$ entry occurred. $\mathrm{B}$, pseudocolor images of the fura-2 340/380 ratio at various time points of the stimulation protocol described in A. C, average traces \pm S.E.M. of the CCE response of HEK-AC8 cells transfected with pcDNA, Orai1, STIM1, or Orai1 and STIM1 together. D, the peak $\left[\mathrm{Ca}^{2+}\right]_{\mathrm{i}}$ response was quantified at 7 min, and the initial rates of $\mathrm{Ca}^{2+}$ entry of the traces depicted in $\mathrm{C}$ were calculated between 6 and 6.5 min, and normalized to that of control cells expressing empty pcDNA vector. E, average traces \pm S.E.M. of the $\mathrm{Ca}^{2+}$ entry occurring upon addition of extracellular Ca ${ }^{2+}$ in the absence of TG pretreatment. $\mathrm{F}$, the peak $\left[\mathrm{Ca}^{2+}\right]_{\mathrm{i}}$ response and the initial rate of $\mathrm{Ca}^{2+}$ entry of the traces depicted in $\mathrm{E}$ were quantified as in $\mathrm{D}$ and normalized to that of control cells expressing empty pcDNA vector. ***, $p<0.001 ; * *, p<0.01 ; *, p<0.05$; and n.s., $p>0.05$ relative to pcDNA transfected controls in a one-way ANOVA followed by Newman-Keuls' post test. 
It is noteworthy, however, that when STIM1 was overexpressed on its own, the $\mathrm{Ca}^{2+}$ leak caused a small but significant activation of AC8. This result suggests that overexpressing STIM1 gives rise to a component of consti- tutive CCE. Coexpressing Orai1 with STIM1 reduced this effect, as the $\mathrm{Ca}^{2+}$ entry occurring in store-replete conditions in the presence of both proteins did not significantly activate AC8.

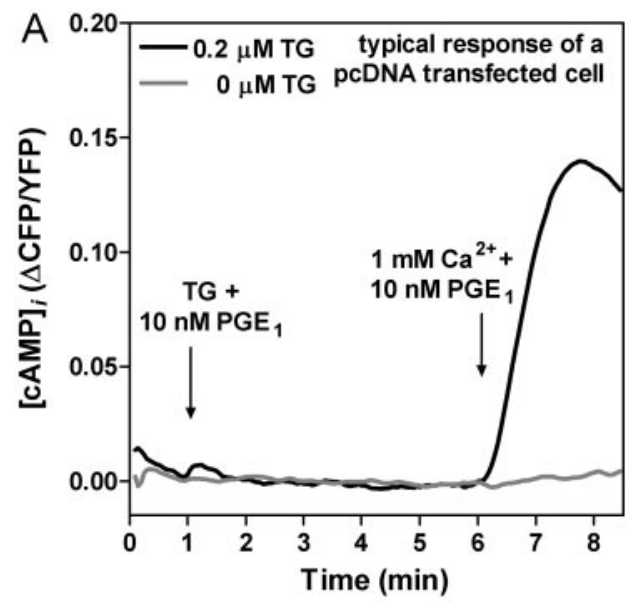

B
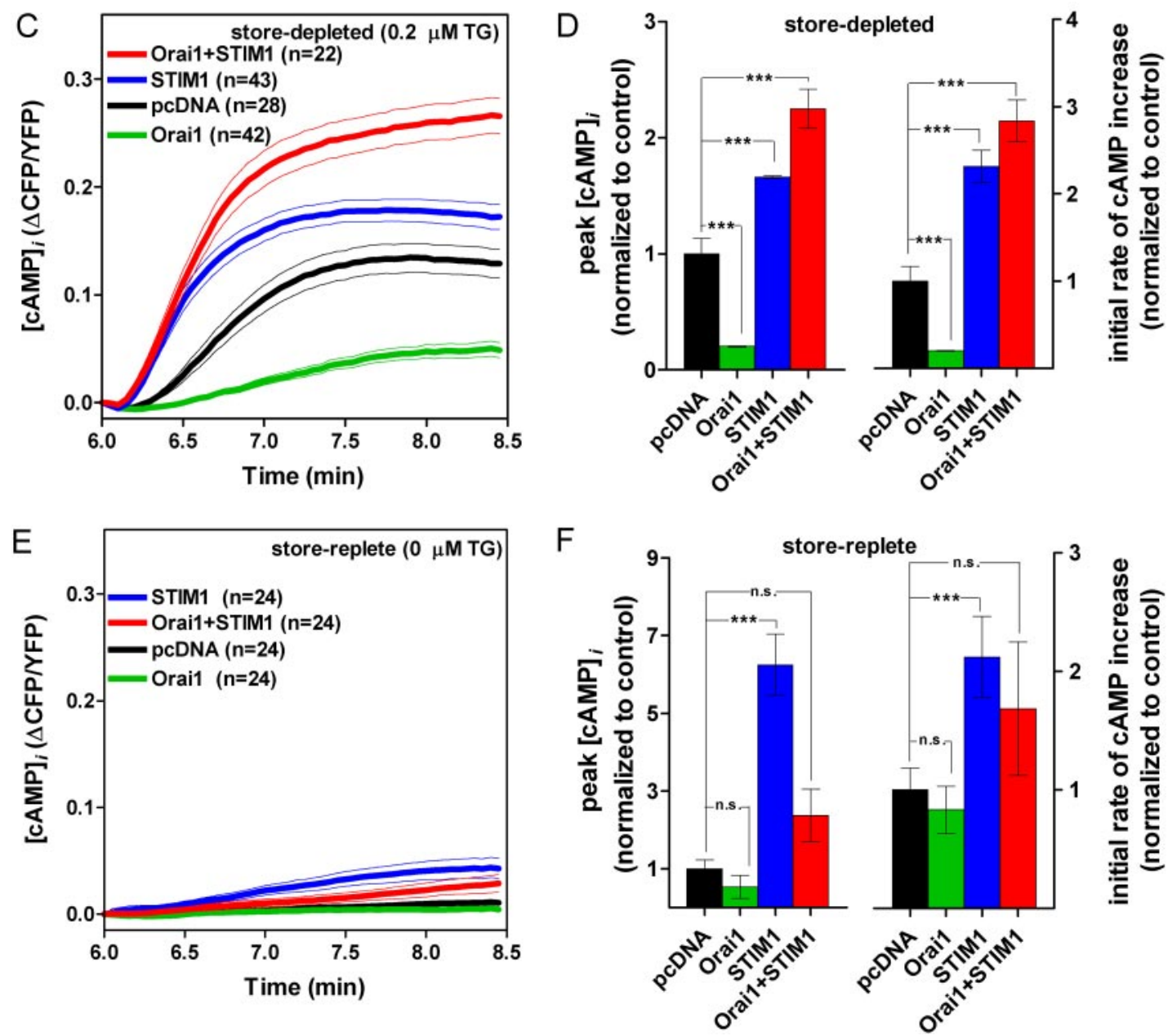

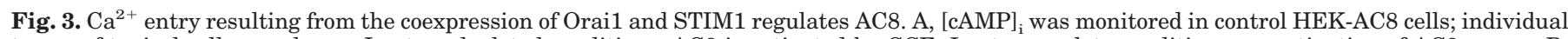

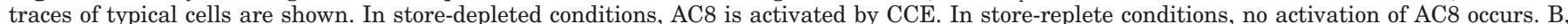

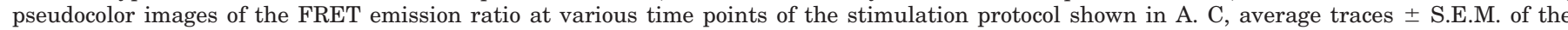

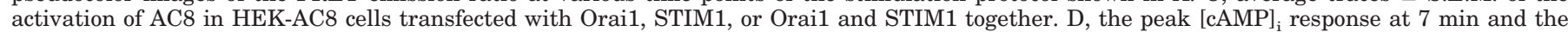

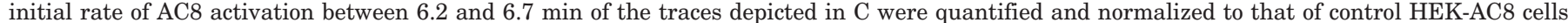

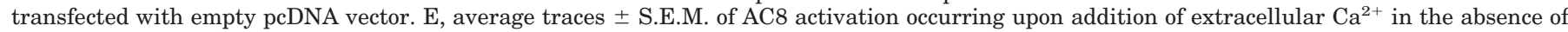

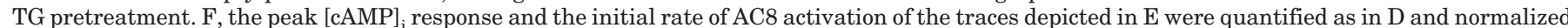

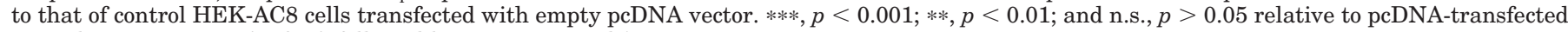
controls in a one-way ANOVA followed by Newman-Keuls' post test. 
ML-9, an Inhibitor of STIM1 Puncta Formation and CCE, Prevents the Activation of AC8 in HEK293 Cells. The lipid raft colocalization of AC8 with Orai1 and STIM1 (Fig. 1), together with the enhanced activation of AC8 by $\mathrm{Ca}^{2+}$ entry in cells overexpressing Orai1 and STIM1 (Fig. 3), provides evidence for a close association between these three signaling molecules. To further examine the interaction between STIM1 and the $\mathrm{Ca}^{2+}$ regulated AC, a pharmacological tool was used to disrupt translocation of endogenous STIM1 to the plasma membrane in response to store depletion. ML-9, a piperazine-based MLCK inhibitor has previously been shown to inhibit CCE (Watanabe et al., 1996; Norwood et al., 2000; Tran et al., 2001). The effects of ML9 on CCE suggested a role for MLCK in store-mediated $\mathrm{Ca}^{2+}$ entry. ML9 has shown to inhibit CCE in HEK293 cells by its inhibition of STIM1 recruitment (Smyth et al., 2008). Here, the effect of ML-9 was examined both on CCE and on the associated degree of AC8 activation.

Fura2-based $\left[\mathrm{Ca}^{2+}\right]_{\mathrm{i}}$ measurements in HEK-AC8 cells were used to obtain dose-response data for the effectiveness of ML9 on CCE inhibition (Fig. 4B). ML9 $(100 \mu \mathrm{M})$ produced $\sim 79 \%$ inhibition of CCE in response to $2 \mathrm{mM} \mathrm{Ca}^{2+}$, after a 10-min pretreatment with $200 \mathrm{nM}$ TG in $\mathrm{Ca}^{2+}$-free conditions. The $\mathrm{IC}_{50}$ for ML9 with respect to CCE was $\sim 10 \mu \mathrm{M}$ (see Fig. 4, B and E). Treatment with ML-9 did not markedly affect the amplitude of TG response, which suggested that the inhibitor did not significantly affect release of $\mathrm{Ca}^{2+}$ from intracellular stores (data not shown). Both the peak rise in intracellular $\left[\mathrm{Ca}^{2+}\right]$ and the initial rate of $\mathrm{Ca}^{2+}$ entry via CCE channels were dramatically attenuated by pretreatment with 10 or $100 \mu \mathrm{M}$ ML-9 (Fig. $4 \mathrm{E}$ ). The ability of 100 $\mu \mathrm{M}$ ML-9 to preclude the translocation of YFP-STIM1 to the plasma membrane upon Tg-mediated store depletion in HEK-AC8 cells was confirmed in confocal imaging experiments (Fig. 4A).

To examine the effects of ML9 on CCE-stimulated AC8 activity, parallel single-cell cAMP measurements in HEKAC8 cells transiently expressing the cAMP sensor Epac1camps were performed. On average, cells exhibited a $\sim 90 \%$ reduction in the peak increase and initial rate of CCE-evoked AC8 activity after pretreatment with $100 \mu \mathrm{M}$ ML-9 (Fig. 4, D and F). Consistent with our fura-2 data, $10 \mu \mathrm{M}$ ML9 attenuated CCE-mediated cAMP production by around $57 \%$ compared with controls. These data support a dependence of $\mathrm{Ca}^{2+}$-stimulated AC8 activity on the translocation of STIM1 to the plasma membrane upon store depletion, and the activation of STIM1-associated CCE.

Effect of CCE Inhibitors on the Regulation of $\mathrm{Ca}^{2+}$. Dependent ACs in an Endogenous System. To address whether AC8 can act as a reliable sensor for CCE in its native environment, we examined the effect of CCE inhibitors on the regulation of $\mathrm{Ca}^{2+}$-dependent $\mathrm{ACs}$ by $\mathrm{CCE}$ in a system in which all proteins are expressed endogenously. Insulin-secreting MIN6 cells were chosen because AC8 is endogenously expressed in pancreatic $\beta$-cells and is thought to provide a key site for cross-talk between cAMP and $\mathrm{Ca}^{2+}$ signaling pathways in the control of insulin release (Delmeire et al., 2003). Furthermore, cultured MIN6 cells have previous been shown to be suitable for expression of the Epac1-camps sensor (Landa et al., 2005). Semiquantitative PCR of MIN6 cell cDNA was performed to establish the presence of both AC6 and AC8 mRNA in this cell type (Fig. 5A, lane 2 and lane 3, respectively) as shown previously for the orthologous rat INS-1 pancreatic $\beta$-cells (Delmeire et al., 2003). Primers for AC2 were used as a negative control and, as expected, no band was detected for AC2 mRNA. Relative mRNA expression levels of $43.4 \pm 3.7$ and $5.8 \pm 0.5$ for AC6 and AC8, respectively were estimated from a semiquantitative PCR analysis (see Materials and Methods).

To examine whether $\mathrm{Ca}^{2+}$ could regulate endogenous AC activity in the MIN6 cells, CCE was induced upon addition of $2.5 \mathrm{mM} \mathrm{Ca}^{2+}$ to the bath solution, after prior store depletion with $1 \mu \mathrm{M}$ Tg in $\mathrm{Ca}^{2+}$-free conditions. Fura- $2 \mathrm{Ca}^{2+}$ measurements confirmed that robust increases in cytosolic $\mathrm{Ca}^{2+}$ levels were triggered using this protocol (Fig. 5B). A recent study by Tamarina et al. (2008) established that STIM1 is expressed in MIN6 cells and that it translocates to the cell periphery upon store depletion, which suggests that it is an important component of CCE within this cell type. However, although pretreatment of MIN6 cells with $100 \mu \mathrm{M}$ ML-9 significantly reduced the initial rate of $\mathrm{CCE}$, the amplitude of the CCE response evoked by $2.5 \mathrm{mM} \mathrm{Ca}^{2+}$ addition was not significantly attenuated (Fig. 5C). These data suggest that ML-9, although an effective inhibitor of CCE in HEK293 cells (see Fig. 4 and Smyth et al., 2008), is a relatively poor inhibitor of CCE events in MIN6 cells.

On the other hand, the study by Tamarina et al. (2008) showed that 2-APB effectively inhibits STIM1 translocation and subsequent CCE in the MIN6 cells. Furthermore, 2-APB has recently been found to inhibit STIM1 puncta formation in HEK293 cells (DeHaven et al., 2008). We therefore tested the ability of 2-APB to inhibit CCE and the responses of the endogenous AC activity to CCE in our MIN6 cells. Consistent with the study of Tamarina et al. (2008), pretreatment with $100 \mu \mathrm{M} 2$ 2-APB significantly reduced CCE in the MIN6 cells (Fig. $5 \mathrm{~B}$ and C). Cells were also treated with $10 \mu \mathrm{M}$ nifedipine to assess whether any of the effects seen were due to changes in L-type $\mathrm{Ca}^{2+}$ channel activity. Data in Fig. 5, B and $\mathrm{C}$ reveal that 1 ) voltage-gated calcium channel activity did not contribute significantly to the $\mathrm{Ca}^{2+}$ entry using the CCE protocol in MIN6 cells and 2) the inhibitory effects of 2-APB were independent of L-type $\mathrm{Ca}^{2+}$ channel activity. We cannot exclude the possibility that 2-APB might partially inhibit TRPC cation channels directly via an extracellular site (Lievremont et al., 2005; Xu et al., 2005) in the MIN6 cells. Such TRPC channels may form associations with STIM1 and Orai as part of the CCE apparatus (Ambudkar et al., 2007). Nevertheless, we can conclude that CCE in MIN6 cells is significantly inhibited (by $\sim 65 \%$ ) after 2 -APB pretreatment compared with controls.

Having established that 2-APB was an effective inhibitor of CCE in MIN6 cells, we examined the effects of this compound on CCE-evoked AC activity in the cells using the cytosolic Epac1-camps sensor. As before, cells were treated with $1 \mu \mathrm{M}$ TG in $\mathrm{Ca}^{2+}$ free conditions $( \pm 100 \mu \mathrm{M} 2 \mathrm{APB})$, and 10 min later CCE was evoked by addition of $2.5 \mathrm{mM}$ $\mathrm{Ca}^{2+}$. Twenty nanomolar forskolin and $100 \mu \mathrm{M} 3$-isobutyl1-methylxanthine were added from 1 min onward to amplify the cAMP signal. FRET measurements revealed a small increase in cAMP signal $(\sim 1.5 \%$ CFP/YFP ratio shift) under control conditions (Fig. 5D). One likely explanation for the relatively modest degree of AC stimulation in response to CCE is the endogenous expression of the $\mathrm{Ca}^{2+}$-inhibited AC6 in MIN6 cells (Fig. 5A, lane 2), which 
may counter any stimulatory effects of CCE on AC8 activity. Nevertheless, the rise in cAMP production evoked by CCE was significantly reduced in cells pretreated with 2APB (see Fig. 5 D\&F). In an attempt to further enhance the cAMP signal, experiments were performed using $5 \mathrm{mM}$
$\mathrm{Ca}^{2+}$ to evoke CCE. However, this gave rise to a predominantly inhibitory effect on cAMP production, which was presumably mediated via the coexisting AC6 (Fig. 5E). This inhibitory response was also significantly attenuated by pretreatment with 2-APB (Fig. 5, E and F).
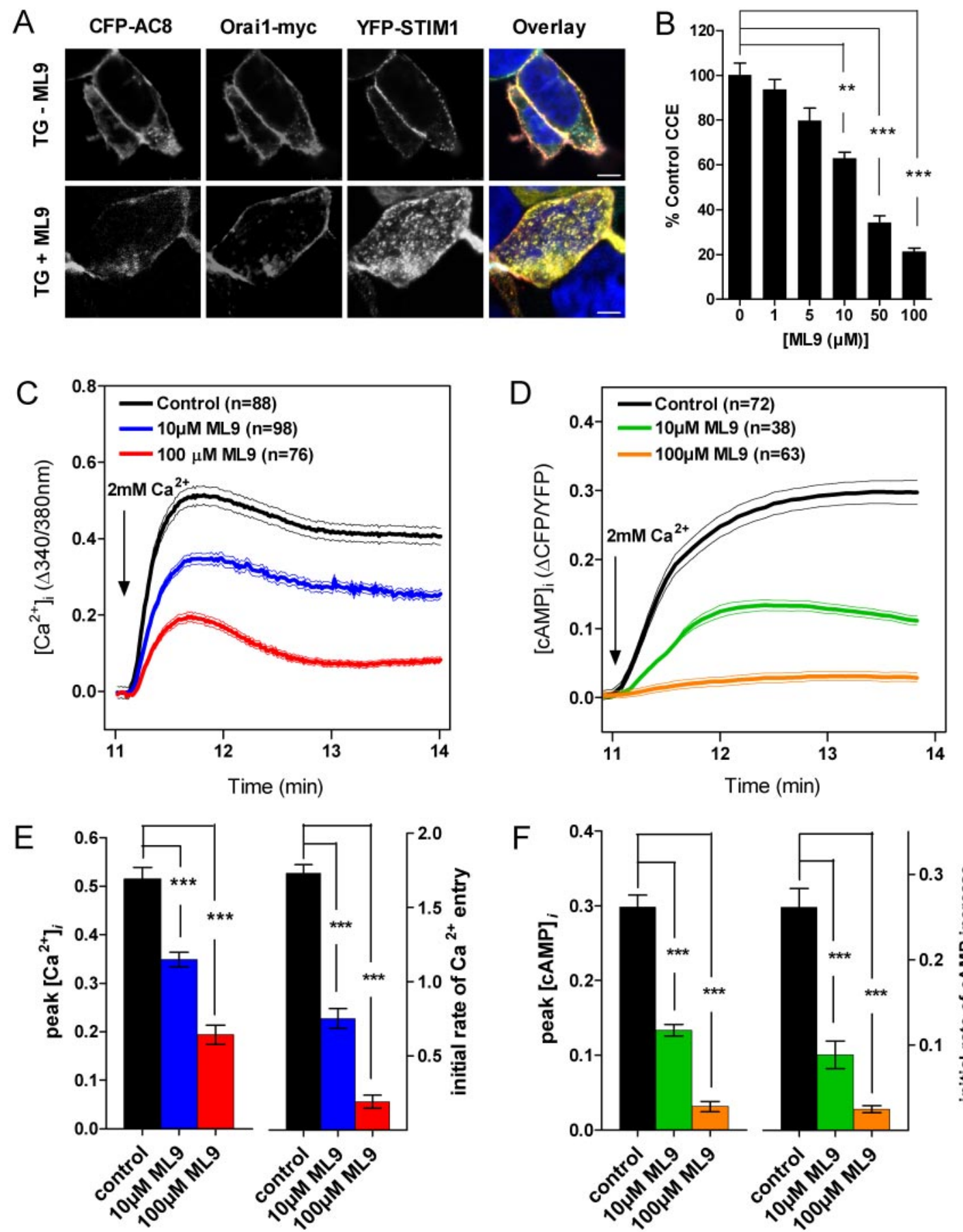

Fig. 4. ML-9, an inhibitor of CCE, prevents the activation of AC8 by STIM1-mediated $\mathrm{Ca}^{2+}$ entry in HEK293 cells. A, confocal analysis of HEK293 cells coexpressing Orai1-myc, YFP-STIM1, and CFP-AC8 after store depletion with $200 \mathrm{nM}$ TG in the presence and absence of ML9. Pretreatment with $100 \mu \mathrm{M}$ ML9 (lower panels) limits translocation of STIM1 to the plasma membrane. Orai1-myc is shown in red, YFP-STIM1 in yellow, AC8-CFP in cyan, and 4,6-diamidino-2-phenylindole staining of the nucleus is in dark blue. B, dose-dependent effects of ML9 pretreatment on CCE in Fura-2 loaded HEK-AC8 cells. Each bar represents peak $\mathrm{Ca}^{2+}$ entry during CCE relative to control conditions (mean \pm S.E.M., $n$ values range from $43-98$ ), Cells were incubated in $\mathrm{Ca}^{2+}$-free conditions in the presence of $0.2 \mu \mathrm{M}$ TG and the presence or absence of ML-9 for 10 min, followed by the addition of $2 \mathrm{mM} \mathrm{Ca}^{2+}$. C, comparison of the effects of 10 and $100 \mu \mathrm{M}$ ML9 on CCE in Fura2-loaded HEK-AC8 cells. Average traces \pm S.E.M. of the Ca ${ }^{2+}$ entry occurring upon addition of extracellular $\mathrm{Ca}^{2+}$ are shown. D, ML-9 pretreatment prevents the activation of AC8 by CCE in a dose-dependent manner. HEK-AC8 cells expressing the Epac1-camps sensor were stimulated as described in A to measure [cAMP] $]_{\mathrm{i}}$. Average traces \pm S.E.M. are shown. E, the peak $\left[\mathrm{Ca}^{2+}\right]_{\mathrm{i}}$ response and the initial rate of $\mathrm{Ca}^{2+}$ entry of the traces depicted in $C$ were calculated. $\mathrm{F}$, the peak $[\mathrm{cAMP}]_{\mathrm{i}}$ response and the initial rate of AC8 activation of the traces depicted in D were quantified. ***, $p<0.001$ in a Student's $t$ test. 
A

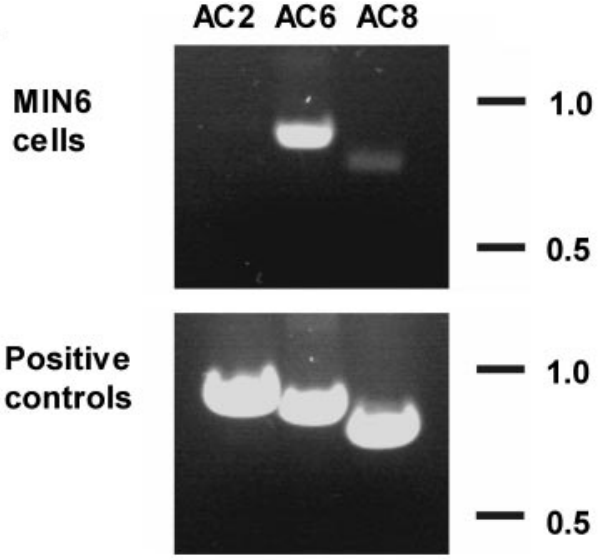

C
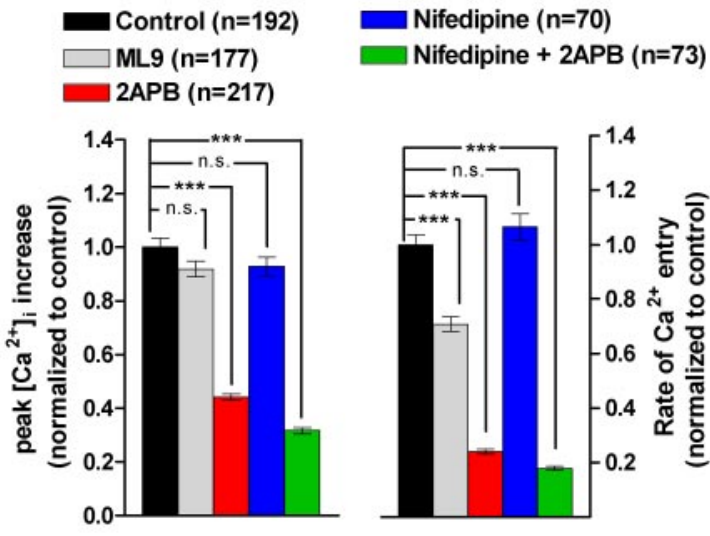

E

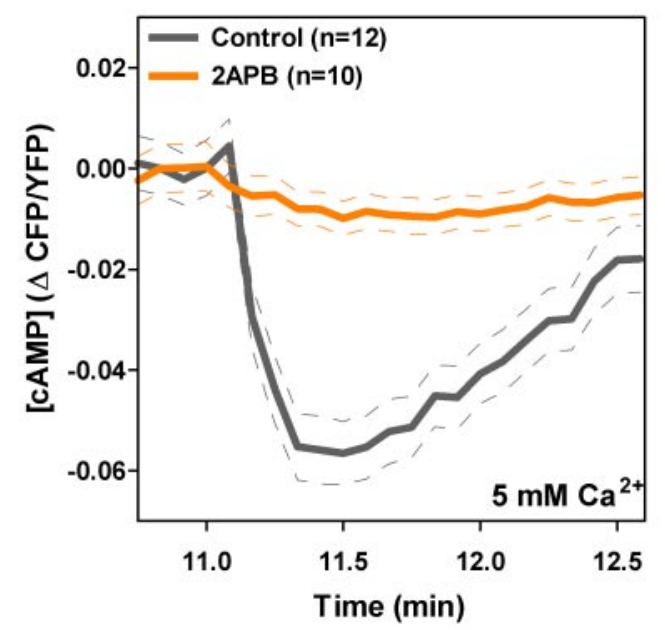

$\mathrm{B}$

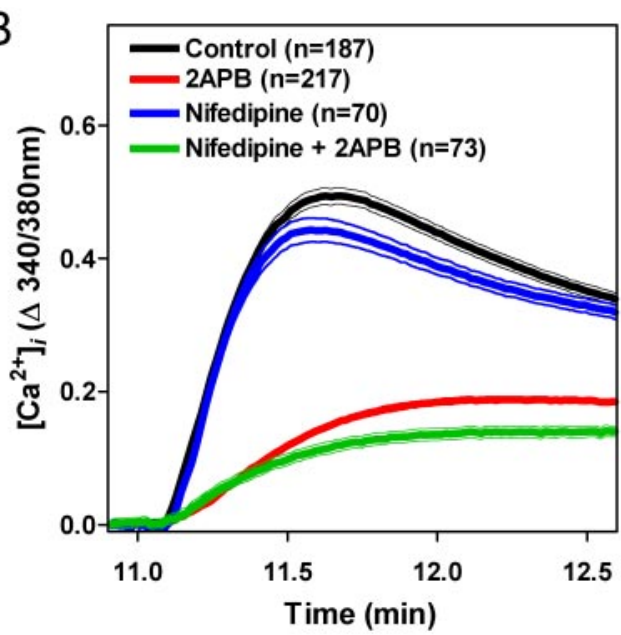

AC stimulation

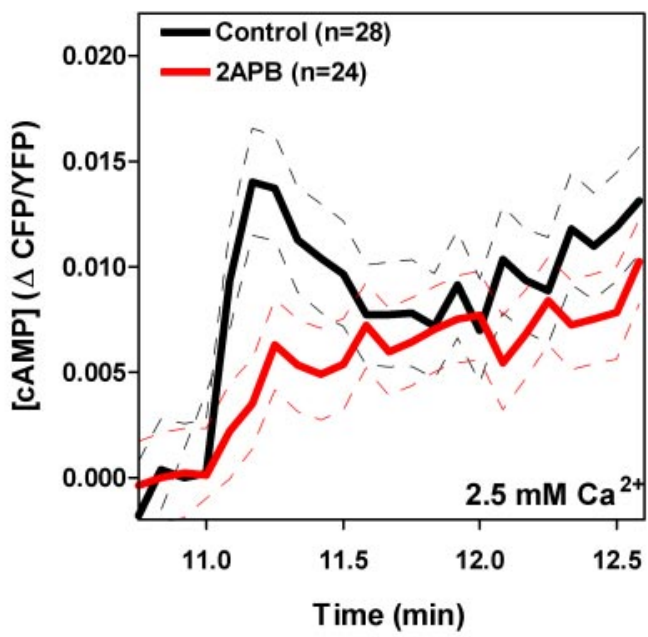

$\mathrm{F}$ \begin{tabular}{l}
$2.5 \mathrm{mM} \mathrm{Ca}$, Control $(\mathrm{n}=28) \quad 5 \mathrm{mM} \mathrm{Ca}$, Control $(\mathrm{n}=12)$ \\
$2.5 \mathrm{mM} \mathrm{Ca}, 2 \mathrm{APB}(\mathrm{n}=24)$ \\
\hline $5 \mathrm{mM} \mathrm{Ca}, 2 \mathrm{~PB}(\mathrm{n}=10)$
\end{tabular}

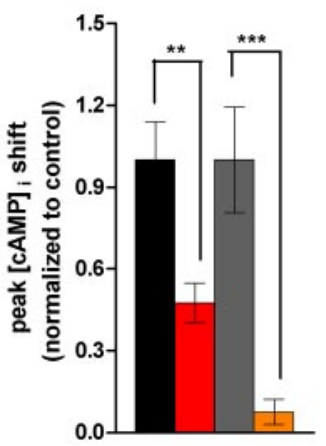

Fig. 5. Effect of CCE inhibitors on the regulation of $\mathrm{Ca}^{2+}$-dependent $\mathrm{ACs}$ in an endogenous system. A, reverse transcription PCR analysis to confirm the presence of mRNA for AC8 and AC6 in insulin-secreting MIN6 $\beta$ cells. B, $\left[\mathrm{Ca}^{2+}\right]_{\mathrm{i}}$ measurements in MIN6 cells loaded with Fura-2 show the CCE response triggered by addition of $2.5 \mathrm{mM} \mathrm{Ca}^{2+}$ subsequent to store depletion with $1 \mu \mathrm{M}$ TG in $\mathrm{Ca}^{2+}$-free saline. Pretreatment with $100 \mu \mathrm{M} 2$-APB significantly attenuates $\mathrm{Ca}^{2+}$ entry in the presence and the absence of the L-type $\mathrm{Ca}^{2+}$ channel inhibitor, $10 \mu \mathrm{M}$ nifedipine. C, the peak $\left[\mathrm{Ca}^{2+}\right]_{i}$ response and initial rate of $\mathrm{Ca}^{2+}$ entry of the traces depicted in B were calculated. D, effect of 2-APB on cAMP levels in response to CCE triggered with $2.5 \mathrm{mM} \mathrm{Ca}^{2+}$ after store depletion with $1 \mu \mathrm{M}$ TG. E, effect of 2-APB on cAMP levels in MIN6 cells in response to CCE triggered with 5 mM Ca ${ }^{2+}$ after store depletion with $1 \mu \mathrm{M}$ TG. F, the peak $[\mathrm{cAMP}]_{\mathrm{i}}$ response and initial rate of cAMP increase of the traces depicted in D and E were calculated. ***, $p<0.001 ; * *, p<0.01$; and n.s., $p>0.05$ relative to pcDNA-transfected controls in a Student's $t$ test. 


\section{Discussion}

STIM1 and Orai1 are proposed to reconstitute CCE (Mercer et al., 2006; Soboloff et al., 2006), STIM1 being the sensor of $\mathrm{Ca}^{2+}$ stores (Liou et al., 2005; Roos et al., 2005), which resides in the membrane of the ER. Upon store depletion, STIM1 clusters into puncta adjacent to the plasma membrane (Stathopulos et al., 2006; Wu et al., 2006), where it activates Orai1, which forms the channel component (Feske et al., 2006; Prakriya et al., 2006; Yeromin et al., 2006). However, additional components, such as TRPC subunits (Liao et al., 2007; Ong et al., 2007), are proposed to contribute to the CCE apparatus, such that it is not clear whether Orai1 and STIM1 alone could reconstitute fully functional CCE. It is well established that AC8 is selectively activated by CCE over any other form of $\mathrm{Ca}^{2+}$ entry in nonexcitable cells, and this unique property has previously been used to distinguish arachidonate-activated (Shuttleworth and Thompson, 1999) and OAG-activated $\mathrm{Ca}^{2+}$ entry (Martin and Cooper, 2006) from CCE. In this study, we used this discriminating property of AC8 to try to determine whether the $\mathrm{Ca}^{2+}$ entry resulting from Orai1 and STIM1 expression could regulate $\mathrm{Ca}^{2+}$-sensitive ACs.

Because AC8 must reside in lipid raft microdomains of the plasma membrane to be regulated by CCE (Smith et al., 2002), and a body of evidence places this enzyme in very close apposition to CCE channels (Fagan et al., 1998; Gu and Cooper, 2000), we considered the possibility that Orai1 and STIM1 might also be expected in these microdomains. Confocal analysis of cells expressing CFP-AC8, YFP-STIM1, and Orai1-myc showed clear colocalization at the plasma membrane upon store depletion. In addition, a sucrose gradientbased fractionation of membranes from cells coexpressing AC8-HA, Orai1-myc, and STIM1 revealed that all three proteins cosedimented in the buoyant fractions with caveolin, a marker of lipid rafts. The presence of STIM1, an ER protein, in lipid raft domains may result from interactions with other proteins that are located in lipid rafts in the plasma membrane, or it may be due to its targeting to lipid raft-like domains of the ER (Browman et al., 2006). In either case, the colocalization after store-depletion of Orai1, STIM1, and AC8, both at the plasma membrane and in lipid rafts, provides one element of support for the selective effects of CCE on $\mathrm{Ca}^{2+}$-regulated ACs. However, it should be noted that colocalization of proteins in raft fractions does not necessarily imply that these proteins are in the same rafts.

Coexpression of Orai1 and STIM1 in HEK-AC8 cells enhanced CCE relative to control cells (Fig. 2C). However, the magnitude of the amplification observed, though highly significant, was less dramatic ( $\sim 1.5$-fold $)$ than in other studies in HEK293 cells (Mercer et al., 2006; Soboloff et al., 2006). Because other components, such as TRPC subunits, have been suggested to form part of the CCE apparatus, it is conceivable that another component may be limiting in the HEK293 cells used in this study. Previous work has suggested the localization of TRPC1, TRPC3, TRPC4, and TRPC5 in lipid raft domains (Ambudkar et al., 2004; Brownlow and Sage, 2005; Ambudkar, 2006). The localization of TPRC1 in these rafts seems to be essential for its role in store-mediated $\mathrm{Ca}^{2+}$ entry, which was confirmed using caveolin knock-out mice (Murata et al., 1995). It is noteworthy that the targeting of TRPC1 to lipid rafts has recently been linked to an association of the protein with STIM1, with both proteins accumulating in cholesterol-rich microdomains of the plasma membrane upon store depletion (Alicia et al., 2008; Pani et al., 2008). Thus, we must be open to the possibility that the components of the $\mathrm{CCE}$ complex regulating AC8 may include TRPC channels that are not limiting in the HEK293 background.

In any case, the increased $\mathrm{Ca}^{2+}$ entry resulting from coexpression of Orai1 and STIM1 significantly enhanced the activation of $\mathrm{AC} 8$, which provides further evidence that these two proteins reconstitute CCE. Moreover, the amplification of $\mathrm{Ca}^{2+}$ entry $(\sim 1.5$-fold $)$ was comparable with that of AC8 activation $(\sim 2.2$-fold $)$. Although the enhancement in $\mathrm{Ca}^{2+}$ entry was modest, it activated AC8 with even greater efficiency, reinforcing the ability of AC8 to function as a sensitive sensor of CCE. Investigating the effects of the individual expression of Orai1 and STIM1 also provided some useful insights into the mechanism of action of these proteins. Expression of Orai1 alone decreased $\mathrm{Ca}^{2+}$ entry (Fig. 2C), and this decrease was mirrored in a reduced activation of AC8 (Fig. 3C). This observation, consistent with the literature (Mercer et al., 2006; Soboloff et al., 2006), has been suggested to result from the likely requirement of several STIM1 molecules to activate an Orai1 molecule. In agreement with previous studies (Mercer et al., 2006; Soboloff et al., 2006), STIM1 expression alone caused a modest increase in CCE (Fig. 2C), which resulted in an increase in AC8 activation of similar amplitude (Fig. 3, C and D). This suggests that endogenous levels of STIM1 may be limiting in these HEK293 cells.

The effect of Orai1 and STIM1 expression on the $\mathrm{Ca}^{2+}$ leak, which occurs in store-replete conditions upon addition of extracellular $\mathrm{Ca}^{2+}$, was also investigated. Similar to results from a previous report (Soboloff et al., 2006), Orai1 and STIM1 expression had only very modest effects on the $\mathrm{Ca}^{2+}$ entry in the absence of TG-treatment. These data confirm that Orai1 and STIM1 coexpression specifically enhances store-dependent $\mathrm{Ca}^{2+}$ entry. However, in the presence of STIM1, a small but significant activation of AC8 occurred in the absence of TG treatment (Fig. $3 \mathrm{E}$ and $4 \mathrm{~F}$ ), suggesting that overexpression of STIM1 gives rise to a small component of constitutive CCE. This may be due to saturation of STIM1 expression in the ER leading to an increased presence of STIM1 in subplasmalemmal puncta, even in store-replete conditions. When Orai1 and STIM1 are coexpressed, the $\mathrm{Ca}^{2+}$ leak is still increased relative to controls, in agreement with another report (Mercer et al., 2006) but to a lesser extent. It is conceivable that the increased expression of Orai1 may decrease the probability of sufficient STIM1 proteins to cluster and activate a channel.

To validate the ability of endogenously expressed STIM1 and Orai1 to regulate AC8 activity, the piperazine-based compound ML-9, which inhibits STIM1 translocation to the cell periphery (Smyth et al., 2008) (Fig. 4A) and thereby STIM1-dependent CCE, was assessed. ML-9 dramatically inhibited both $\mathrm{CCE}$ - and $\mathrm{Ca}^{2+}$-dependent $\mathrm{AC} 8$ activation in HEK-AC8 cells in a dose-dependent manner (Fig. 4), strongly linking these two events. The efficacy of ML-9 raises an unresolved issue with regard to its mechanism of action. Although first identified as an MLCK inhibitor, a study by Smyth et al. (2008) suggested that ML-9 inhibited CCE independently of MLCK. On the other hand, Norwood et al. 
(2000) and Watanabe et al. (1996) believed that ML-9 acted against CCE because of its inhibition of MLCK. These latter proposals resonate with the known requirement for STIM1 movement between the ER and the plasma membrane, which is thought to be facilitated by microtubules (Smyth et al., 2007) and supported by evidence that STIM1 acts as a microtubule growing end tracker (Grigoriev et al., 2008). Nevertheless, dissecting the precise role of the actomyosin framework in coupling dynamic CCE events to AC8 activity is a considerable experimental challenge.

Although the studies with overexpressed proteins in HEK293 cells strongly supported the interdependence of Orai1, STIM1, and AC8, a native setting can provide a more compelling argument for essential interdependences. We selected the insulin-secreting cell line MIN6, which by PCR analysis expressed both the $\mathrm{Ca}^{2+}$-stimulated AC8 and the $\mathrm{Ca}^{2+}$-inhibited AC6. Using 2-APB as a pharmacological tool to inhibit STIM1 translocation in the cells (Tamarina et al., 2008), we found that CCE-mediated stimulation of endogenous AC8 activity is also inhibited. As a bonus, we could monitor the responsiveness of the $\mathrm{Ca}^{2+}$-inhibitable AC6. Coexistence of AC8 and the relatively highly expressed AC6 in the MIN6 cells probably explains the modest degree of $\mathrm{Ca}^{2+}$. dependent stimulation of cAMP accumulation that was detected when CCE was evoked using $2.5 \mathrm{mM}$ external $\mathrm{Ca}^{2+}$. Previous studies in $\mathrm{C} 6-2 \mathrm{~B}$ glioma cells showed that AC6 inhibition is also selective for CCE over other types of $\mathrm{Ca}^{2+}$ increase (Chiono et al., 1995) and so could also be expected to be a sensor for CCE in MIN6 cells. Indeed, CCE induced upon addition of $5 \mathrm{mM}$ external $\mathrm{Ca}^{2+}$ evoked a predominantly inhibitory effect on cAMP production (presumably mediated via AC6); this inhibition was significantly attenuated after pretreatment with 2-APB.

The ability to demonstrate clear regulation of the $\mathrm{Ca}^{2+}$ sensitive ACs in their native environment significantly supports the hypothesis that AC8, and AC6, reside close to $\mathrm{CCE}$ channels. The fact that the $\mathrm{Ca}^{2+}$ entry resulting from Orai1 and STIM1 expression regulates AC8 prompts a consideration of the possibility that these proteins may form part of a larger signaling complex. The possibility of an AC-based signaling complex is being gradually strengthened by a growing list of proteins, reported to associate with ACs, such as A-kinase anchoring proteins (Bauman et al., 2006), phosphodiesterases (Willoughby et al., 2006), protein phosphatase 2A (Crossthwaite et al., 2006), caveolin (Head et al., 2005), and the guanine nucleotide exchange factor Ric8a (Wang et al., 2007). Thus it may not be too fanciful to consider a physical association between ACs and the elements of the CCE apparatus, although for the moment no "bridging mechanism" is apparent. Residence in lipid rafts alone is clearly not sufficient to ensure regulation of AC 8 by a $\mathrm{Ca}^{2+}$ channel, because OAG-activated TRPC channels (such as TRPC3), which are also located in lipid rafts (Lockwich et al., 2000), do not activate AC8 (Martin and Cooper, 2006). However, we could not detect direct interactions between AC8 and Orai1 or STIM1 by coimmunoprecipitation when all three proteins were overexpressed in HEK293 cells (data not shown), which suggests that any interactions between these proteins may be weak or transient, or unable to withstand the solubilization conditions. Other strategies, not involving disruption of cells, may be more discerning, such as those involving Förster resonance energy transfer of tagged proteins, which has recently been used to show direct interactions between Orai1 and STIM1 (Muik et al., 2008). We must also acknowledge that we cannot exclude a role for other channel partners in the CCE complexes. It is quite feasible that a background of, for instance, certain TRPC molecules might participate in the assembly of the CCE apparatus (Yuan et al., 2007; Ma et al., 2008) the regulatory consequences of which we are studying. However, whatever the background, it is clear that in the present experimental situation, the increment in CCE regulation of AC8 is due only to the expression of STIM1 and Orai1.

For the present, we may conclude that expression of Orai1 and STIM1 is sufficient to regulate AC8 in a heterologous system and that the same situation occurs in an endogenous system for both AC8 and AC6. These findings validate Orai1 and STIM1 as participants in CCE and at the same time reinforce ACs as discriminating sensors. Obviously mysteries remain in terms of the precise molecular events underlying the dynamic assembly and organization of CCE complexes, but regardless of the new details that will emerge, it seems likely that $\mathrm{Ca}^{2+}$-sensitive ACs will continue to remain intimate and informative associates.

\section{References}

Alicia S, Angélica Z, Carlos S, Alfonso S, and Vaca L (2008) STIM1 converts TRPC1 from a receptor-operated to a store-operated channel: moving TRPC1 in and out of lipid rafts. Cell Calcium 44:479-491.

Ambudkar IS (2006) $\mathrm{Ca}^{2+}$ signaling microdomains: platforms for the assembly and regulation of TRPC channels. Trends Pharmacol Sci 27:25-32.

Ambudkar IS, Brazer SC, Liu X, Lockwich T, and Singh B (2004) Plasma membrane localization of TRPC channels: role of caveolar lipid rafts. Novartis Found Symp 258:63-70; discussion 70-74, 98-102, 263-266.

Ambudkar IS, Ong HL, Liu X, Bandyopadhyay BC, Bandyopadhyay B, and Cheng KT (2007) TRPC1: The link between functionally distinct store-operated calcium channels. Cell Calcium 42:213-223.

Bauman AL, Soughayer J, Nguyen BT, Willoughby D, Carnegie GK, Wong W, Hosh N, Langeberg LK, Cooper DM, Dessauer CW, et al. (2006) Dynamic regulation of cAMP synthesis through anchored PKA-adenylyl cyclase V/VI complexes. Mol Cell 23:925-931.

Broad LM, Cannon TR, and Taylor CW (1999) A non-capacitative pathway activated by arachidonic acid is the major $\mathrm{Ca}^{2+}$ entry mechanism in rat $\mathrm{A} 7 \mathrm{r} 5$ smooth muscle cells stimulated with low concentrations of vasopressin. J Physiol 517:121-134.

Browman DT, Resek ME, Zajchowski LD, and Robbins SM (2006) Erlin-1 and erlin-2 are novel members of the prohibitin family of proteins that define lipid-raft-like domains of the ER. J Cell Sci 119:3149-3160.

Brownlow SL and Sage SO (2005) Transient receptor potential protein subunit assembly and membrane distribution in human platelets. Thromb Haemost 94: $839-845$.

Chen C and Okayama H (1987) High-efficiency transformation of mammalian cells by plasmid DNA. Mol Cell Biol 7:2745-2752.

Chiono M, Mahey R, Tate G, and Cooper DM (1995) Capacitative Ca2+ entry exclusively inhibits cAMP synthesis in $\mathrm{C} 6-2 \mathrm{~B}$ glioma cells. Evidence that physiologically evoked $\mathrm{Ca}^{2+}$ entry regulates $\mathrm{Ca}^{2+}$-inhibitable adenylyl cyclase in nonexcitable cells. J Biol Chem 270:1149-1155.

Crossthwaite AJ, Ciruela A, Rayner TF, and Cooper DM (2006) A direct interaction between the $\mathrm{N}$ terminus of adenylyl cyclase AC8 and the catalytic subunit of protein phosphatase 2A. Mol Pharmacol 69:608-617.

Crossthwaite AJ, Seebacher T, Masada N, Ciruela A, Dufraux K, Schultz JE, and Cooper DM (2005) The cytosolic domains of $\mathrm{Ca}^{2+}$-sensitive adenylyl cyclases dictate their targeting to plasma membrane lipid rafts. J Biol Chem 280:6380 6391.

DeHaven WI, Smyth JT, Boyles RR, Bird GS, and Putney JW Jr (2008) Complex actions of 2-aminoethyldiphenyl borate on store-operated calcium entry. $J$ Bio Chem 283:19265-19273.

Delmeire D, Flamez D, Hinke SA, Cali JJ, Pipeleers D, and Schuit F (2003) Type VII adenylyl cyclase in rat beta cells: coincidence signal detector/generator for glucose and GLP-1. Diabetologia 46:1383-1393.

Fagan KA, Mahey R, and Cooper DM (1996) Functional co-localization of transfected $\mathrm{Ca}^{2+}$-stimulable adenylyl cyclases with capacitative $\mathrm{Ca}^{2+}$ entry sites. J Biol Chem 271:12438-12444

Fagan KA, Mons N, and Cooper DM (1998) Dependence of the $\mathrm{Ca}^{2+}$-inhibitable adenylyl cyclase of $\mathrm{C} 6-2 \mathrm{~B}$ glioma cells on capacitative $\mathrm{Ca}^{2+}$ entry. $J$ Biol Chem 273:9297-9305.

Fagan KA, Smith KE, and Cooper DM (2000) Regulation of the $\mathrm{Ca}^{2+}$-inhibitable Adenylyl Cyclase type VI by Capacitative $\mathrm{Ca}^{2+}$ Entry requires localization in cholesterol-rich domains. J Biol Chem 275:26530-26537.

Feske S, Gwack Y, Prakriya M, Srikanth S, Puppel SH, Tanasa B, Hogan PG, Lewis RS, Daly M, and Rao A. (2006) A mutation in Orai1 causes immune deficiency by abrogating CRAC channel function. Nature 441:179-185.

Grigoriev I, Gouveia SM, van der Vaart B, Demmers J, Smyth JT, Honnappa S 
Splinter D, Steinmetz MO, Putney JW Jr, Hoogenraad CC, et al. (2008) STIM1 is a MT-plus-end-tracking protein involved in remodeling of the ER. Curr Biol 18:177-182.

Gu C and Cooper DM (1999) Calmodulin-binding sites on adenylyl cyclase type VIII. $J$ Biol Chem 274:8012-8021.

Gu C and Cooper DM (2000) $\mathrm{Ca}^{2+}, \mathrm{Sr}^{2+}$, and $\mathrm{Ba}^{2+}$ identify distinct regulatory sites on adenylyl cyclase (AC) types VI and VIII and consolidate the apposition of capacitative cation entry channels and $\mathrm{Ca}^{2+}$-sensitive ACs. J Biol Chem 275: 6980-6986.

Gwack Y, Srikanth S, Feske S, Cruz-Guilloty F, Oh-hora M, Neems DS, Hogan PG, and Rao A (2007) Biochemical and functional characterization of Orai proteins. $J$ Biol Chem 282:16232-16243.

Head BP, Patel HH, Roth DM, Lai NC, Niesman IR, Farquhar MG, and Insel PA (2005) G-protein-coupled receptor signaling components localize in both sarcolemmal and intracellular caveolin-3-associated microdomains in adult cardiac myocytes. J Biol Chem 280:31036-31044.

Huang GN, Zeng W, Kim JY, Yuan JP, Han L, Muallem S, and Worley PF (2006) STIM1 carboxyl-terminus activates native SOC, I(crac) and TRPC1 channels. Nat Cell Biol 8:1003-1010.

Jardin I, Lopez JJ, Salido GM, and Rosado JA (2008) Orai1 mediates the interaction between STIM1 and hTRPC1 and regulates the mode of activation of hTRPC1forming $\mathrm{Ca}^{2+}$ channels. J Biol Chem 283:25296-25304.

Landa LR Jr, Harbeck M, Kaihara K, Chepurny O, Kitiphongspattana K, Graf O, Nikolaev VO, Lohse MJ, Holz GG, and Roe MW (2005) Interplay of $\mathrm{Ca}^{2+}$ and cAMP signaling in the insulin-secreting MIN6 beta-cell line. J Biol Chem 280:3129431302 .

Liao Y, Erxleben C, Abramowitz J, Flockerzi V, Zhu MX, Armstrong DL, and Birnbaumer L (2008) Functional interactions among Orai1, TRPCs, and STIM suggest a STIM-regulated heteromeric Orai/TRPC model for SOCE/Icrac channels. Proc Natl Acad Sci U S A 105:2895-2900.

Liao Y, Erxleben C, Yildirim E, Abramowitz J, Armstrong DL, and Birnbaumer L (2007) Orai proteins interact with TRPC channels and confer responsiveness to store depletion. Proc Natl Acad Sci U S A 104:4682-4687.

Lievremont JP, Bird GS, and Putney JW Jr (2005) Mechanism of inhibition of TRPC cation channels by 2-aminoethoxydiphenylborane. Mol Pharmacol 68:758-762.

Liou J, Kim ML, Heo WD, Jones JT, Myers JW, Ferrell JE Jr, and Meyer T (2005) STIM is a $\mathrm{Ca}^{2+}$ sensor essential for $\mathrm{Ca}^{2+}$-store-depletion-triggered $\mathrm{Ca} 2+$ influx. Curr Biol 15:1235-1241.

Lockwich TP, Liu X, Singh BB, Jadlowiec J, Weiland S, and Ambudkar IS (2000) Assembly of Trp1 in a signaling complex associated with caveolin-scaffolding lipid raft domains. J Biol Chem 275:11934-11942.

López JJ, Salido GM, Pariente JA, and Rosado JA (2006) Interaction of STIM1 with endogenously expressed human canonical TRP1 upon depletion of intracellular $\mathrm{Ca}^{2+}$ stores. J Biol Chem 281:28254-28264.

Luo D, Broad LM, Bird GS, and Putney JW Jr (2001) Signaling pathways underlying muscarinic receptor-induced $\left[\mathrm{Ca}^{2+}\right] \mathrm{i}$ oscillations in HEK293 cells. J Biol Chem 276:5613-5621.

Ma HT, Peng Z, Hiragun T, Iwaki S, Gilfillan AM, and Beaven MA (2008) Canonical transient receptor potential 5 channel in conjunction with Orai1 and STIM1 allows $\mathrm{Sr}^{2+}$ entry, optimal influx of $\mathrm{Ca}^{2+}$, and degranulation in a rat mast cell line. $J$ Immunol 180:2233-2239.

Martin AC and Cooper DM (2006) Capacitative and 1-oleyl-2-acetyl-sn-glycerolactivated $\mathrm{Ca}^{2+}$ entry distinguished using adenylyl cyclase type 8. Mol Pharmacol 70:769-777.

Mercer JC, Dehaven WI, Smyth JT, Wedel B, Boyles RR, Bird GS, and Putney JW Jr (2006) Large store-operated calcium selective currents due to co-expression of Orai1 or Orai2 with the intracellular calcium sensor, Stim1. J Biol Chem 281: 24979-24990.

Muik M, Frischauf I, Derler I, Fahrner M, Bergsmann J, Eder P, Schindl R, Hesch C, Polzinger B, Fritsch R, et al. (2008) Dynamic coupling of the putative coiled-coil domain of ORAI1 with STIM1 mediates ORAI1 channel activation. J Biol Chem 283:8014-8022.

Murata M, Peränen J, Schreiner R, Wieland F, Kurzchalia TV, and Simons K (1995) VIP21/caveolin is a cholesterol-binding protein. Proc Natl Acad Sci USA 92: 10339-10343.

Nakahashi Y, Nelson E, Fagan K, Gonzales E, Guillou JL, and Cooper DM (1997) Construction of a full-length $\mathrm{Ca}^{2+}$-sensitive adenylyl cyclase/aequorin chimera J Biol Chem 272:18093-18097.

Nikolaev VO, Bünemann M, Hein L, Hannawacker A, and Lohse MJ (2004) Novel single chain cAMP sensors for receptor-induced signal propagation. J Biol Chem 279:37215-37218.

Norwood N, Moore TM, Dean DA, Bhattacharjee R, Li M, and Stevens T (2000) Store-operated calcium entry and increased endothelial cell permeability. Am J Physiol Lung Cell Mol Physiol 279:L815-L824.

Ong HL, Cheng KT, Liu X, Bandyopadhyay BC, Paria BC, Soboloff J, Pani B, Gwack Y, Srikanth S, Singh BB, et al. (2007) Dynamic assembly of TRPC1/STIM1/Orai1 ternary complex is involved in store operated calcium influx: Evidence for similarities in SOC and CRAC channel components. J Biol Chem 282:9105-9116.

Pani B, Ong HL, Liu X, Rauser K, Ambudkar IS, and Singh BB (2008) Lipid rafts determine clustering of STIM1 in endoplasmic reticulum-plasma membrane junctions and regulation of store-operated $\mathrm{Ca}^{2+}$ entry (SOCE). J Biol Chem 283: $17333-17340$.
Peinelt C, Vig M, Koomoa DL, Beck A, Nadler MJ, Koblan-Huberson M, Lis A, Fleig A, Penner R, and Kinet JP (2006) Amplification of CRAC current by STIM1 and CRACM1 (Orai1). Nat Cell Biol 8:771-773.

Prakriya M, Feske S, Gwack Y, Srikanth S, Rao A, and Hogan PG (2006) Orai1 is an essential pore subunit of the CRAC channel. Nature 443:230-233.

Roos J, DiGregorio PJ, Yeromin AV, Ohlsen K, Lioudyno M, Zhang S, Safrina O, Kozak JA, Wagner SL, Cahalan MD, et al. (2005) STIM1, an essential and conserved component of store-operated $\mathrm{Ca}^{2+}$ channel function. J Cell Biol 169: $435-445$.

Shuttleworth TJ and Thompson JL (1999) Discriminating between capacitative and arachidonate-activated $\mathrm{Ca}^{2+}$ entry pathways in HEK293 cells. J Biol Chem 274 $31174-31178$

Simons K and Ikonen E. (1997) Functional rafts in cell membranes. Nature 387: $569-572$.

Simpson RE, Ciruela A, and Cooper DM (2006) The role of calmodulin recruitment in $\mathrm{Ca}^{2+}$-stimulation of adenylyl cyclase type 8. J Biol Chem 281:17379-17389.

Smith KE, Gu C, Fagan KA, Hu B, and Cooper DM (2002) Residence of adenylyl cyclase type 8 in caveolae is necessary but not sufficient for regulation by capacitative $\mathrm{Ca}^{2+}$ entry. J Biol Chem 277:6025-6031.

Smyth JT, DeHaven WI, Bird GS, and Putney JW Jr (2007) Role of the microtubule cytoskeleton in the function of the store-operated $\mathrm{Ca}^{2+}$ channel activator STIM1. J Cell Sci 120:3762-3771.

Smyth JT, Dehaven WI, Bird GS, and Putney JW Jr (2008) $\mathrm{Ca}^{2+}$-store-dependent and -independent reversal of Stim1 localization and function. J Cell Sci 121:762772

Soboloff J, Spassova MA, Dziadek MA, and Gill DL (2006) Calcium signals mediated by STIM and Orai proteins-a new paradigm in inter-organelle communication. Biochim Biophys Acta 1763:1161-1168.

Stathopulos PB, Li GY, Plevin MJ, Ames JB, and Ikura M (2006) Stored $\mathrm{Ca}^{2+}$ depletion-induced oligomerization of stromal interaction molecule 1 (STIM1) via the EF-SAM region: An initiation mechanism for capacitive $\mathrm{Ca} 2+$ entry. $J$ Biol Chem 281:35855-35862.

Sunahara RK, Dessauer CW, and Gilman AG (1996) Complexity and diversity of mammalian adenylyl cyclases. Annu Rev Pharmacol Toxicol 36:461-480.

Tamarina NA, Kuznetsov A, and Philipson LH (2008) Reversible translocation of EYFP-tagged STIM1 is coupled to calcium influx in insulin secreting beta-cells. Cell Calcium 44:533-544.

Tran QK, Watanabe H, Le HY, Pan L, Seto M, Takeuchi K, and Ohashi K (2001) Myosin light chain kinase regulates capacitative $\mathrm{Ca}^{2+}$ entry in human monocytes/ macrophages. Arterioscler Thromb Vasc Biol 21:509-515.

Vig M, Beck A, Billingsley JM, Lis A, Parvez S, Peinelt C, Koomoa DL, Soboloff J, Gill DL, Fleig A, et al. (2006) CRACM1 multimers form the ion-selective pore of the CRAC channel. Curr Biol 16:2073-2079.

Wang SC, Lai HL, Chiu YT, Ou R, Huang CL, and Chern Y (2007) Regulation of type $\mathrm{V}$ adenylate cyclase by Ric8a, a guanine nucleotide exchange factor. Biochem $J$ 406:383-388.

Watanabe H, Takahashi R, Zhang XX, Kakizawa H, Hayashi H, and Ohno R (1996) Inhibition of agonist-induced $\mathrm{Ca}^{2+}$ entry in endothelial cells by myosin light-chain kinase inhibitor. Biochem Biophys Res Commun 225:777-784.

Williams RT, Senior PV, Van Stekelenburg L, Layton JE, Smith PJ, and Dziadek MA (2002) Stromal interaction molecule 1 (STIM1), a transmembrane protein with growth suppressor activity, contains an extracellular SAM domain modified by N-linked glycosylation. Biochim Biophys Acta 1596:131-137.

Willoughby D and Cooper DM (2006) $\mathrm{Ca}^{2+}$ stimulation of adenylyl cyclase generates dynamic oscillations in cyclic AMP. J Cell Sci 119:828-836.

Willoughby D and Cooper DM (2007) Organization and $\mathrm{Ca}^{2+}$ regulation of adenylyl cyclases in cAMP microdomains. Physiol Rev 87:965-1010.

Willoughby D, Wong W, Schaack J, Scott JD, and Cooper DM (2006) An anchored PKA and PDE4 complex regulates sub-plasmalemmal cAMP dynamics. EMBO J 25:2051-2061.

Wu MM, Buchanan J, Luik RM, and Lewis RS (2006) $\mathrm{Ca}^{2+}$ store depletion causes STIM1 to accumulate in ER regions closely associated with the plasma membrane. J Cell Biol 174:803-813.

Xu SZ, Zeng F, Boulay G, Grimm C, Harteneck C, and Beech DJ (2005) Block of TRPC5 channels by 2-aminoethoxydiphenyl borate: a differential, extracellular and voltage-dependent effect. Br J Pharmacol 145:405-414.

Yeromin AV, Zhang SL, Jiang W, Yu Y, Safrina O, and Cahalan MD (2006) Molecular identification of the CRAC channel by altered ion selectivity in a mutant of Orai. Nature 443:226-229.

Yuan JP, Zeng W, Huang GN, Worley PF, and Muallem S (2007) STIM1 heteromultimerizes TRPC channels to determine their function as store-operated channels. Nat Cell Biol 9:636-645.

Zhang SL, Yu Y, Roos J, Kozak JA, Deerinck TJ, Ellisman MH, Stauderman KA, and Cahalan MD (2005) STIM1 is a $\mathrm{Ca}^{2+}$ sensor that activates CRAC channels and migrates from the $\mathrm{Ca}^{2+}$ store to the plasma membrane. Nature 437:902-905.

Address correspondence to: Dermot M. F. Cooper, Department of Pharmacology, University of Cambridge, Tennis Court Road, Cambridge, CB2 1PD, United Kingdom. E-mail: dmfc2@cam.ac.uk 